Ghahari et al. / Turkish Journal of Earthquake Research 1 (2), 98-122, December 2019

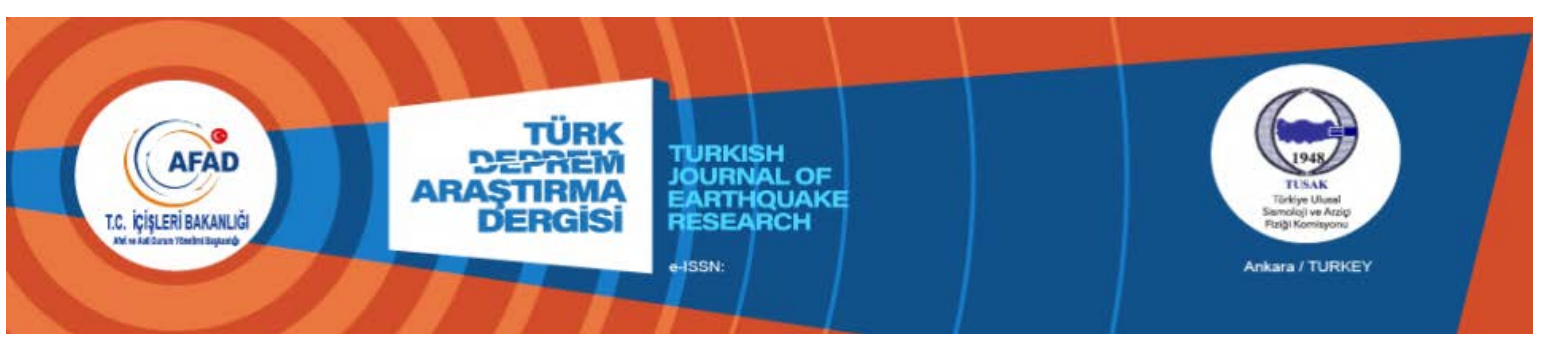

Joint System-Input Identification of Bridge Structures

Seyed Farid Ghahari ${ }^{1}$, Mehmet Çelebi ${ }^{2}$, Hamed Ebrahimian ${ }^{3}$, Barbaros Cetiner ${ }^{1}$ and Ertugrul Taciroglu ${ }^{1}$

${ }^{1}$ Department of Civil \& Environmental Engineering, University of California, Los Angeles

2 United States Geological Survey, Menlo Park, CA

${ }^{3}$ Department of Civil and Environmental Engineering at the University of Nevada, Reno (UNR)

ORCID: 0000-0002-3847-5277, 0000-0002-4769-7357, 0000-0003-1992-6033, 0000-0002-9726-8120, 0000-0001-9618-1210

Keywords

Golden Gate Bridge, Strong Ground Motion, Foundation Input Motions, Soil-Structure Interaction

Highlights

* Novel framework for system identification of bridge structures

* Joint system-input identification solution using sparsely measured earthquake-induced responses

* Direct measurement of the bridge Foundation Input Motions (FIMs)

\section{Acknowledgements}

California Geological Survey (Contract No. 1014-963), California Department of Transportation (Grant No. 65A0450)

\section{Aim}

Presenting a novel framework for system identification of bridge structures using recorded earthquake data

\section{Location}

San Fracisco, CA, USA

\section{Methods}

Joint input-system identification method to reveal the bridge Foundation Input Motions (FIMs)

\section{Results}

A practical double parallel-processing framework has been developed in applying any size structures

\section{Supporting Institutions}

California Geological Survey, California Department of Transportation

\section{Manuscript \\ Research Article}

Received: 18.07.2019

Revised: 22.11.2019

Accepted: 22.11.2019

Printed: 30.12 .2019

DOI

doi.

\section{Corresponding Author}

Ertugrul Taciroglu

Email: etacir@g.ucla.edu
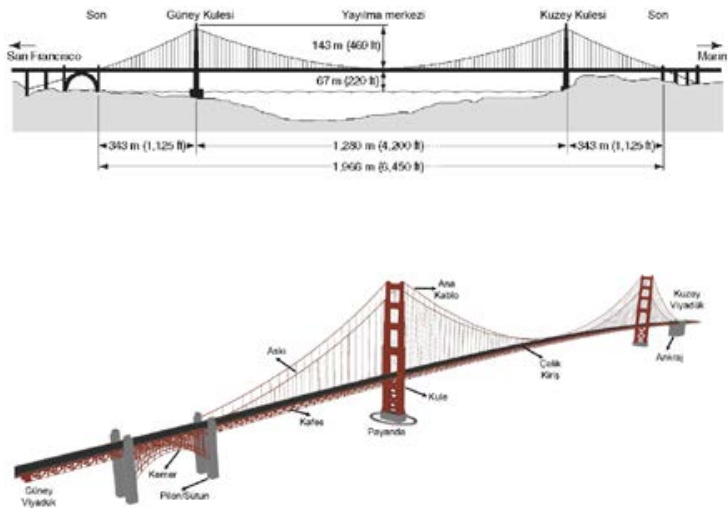

Figure

Dimensions and various parts of the Golden Gate Bridge, San Francisco, CA-USA

\title{
How to cite
}

Ghahari S.F., Çelebi M., Ebrahimian H., Cetiner B., Taciroglu E., 2019. Joint System-Input Identification of Bridge Structures, Turk. J. Earthq. Res. 1 (2), 98-122 
Ghahari et al. / Turkish Journal of Earthquake Research 1 (2), 98-122, December 2019

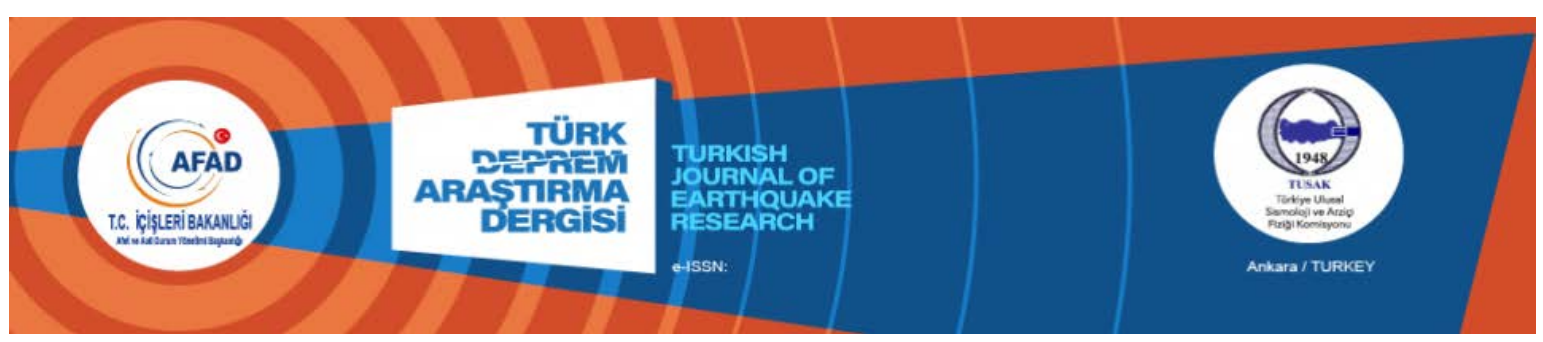

Köprü Yapılarının Eş Zamanlı Sistem ve Girdi Tanılaması

Seyed Farid Ghahari ${ }^{1}$, Mehmet Çelebi ${ }^{2}$, Hamed Ebrahimian ${ }^{3}$, Barbaros Çetiner ${ }^{1}$ and Ertuğrul Taciroğlu ${ }^{1}$

${ }^{1}$ Kaliforniya Üniversitesi, Inşaat ve Çevre Mühendisliği Bölümü, Los Angeles, A.B.D.

${ }^{2}$ Birleşik Devletler Jeolojik Araştırmalar, Menlo Park, Kaliforniya, A.B.D.

${ }^{3}$ Nevada Üniversitesi Inşaat ve Çevre Mühensdisliği Bölümü, Reno (UNR).

ORCID: 0000-0002-3847-5277, 0000-0002-4769-7357, 0000-0003-1992-6033, 0000-0002-9726-8120, 0000-0001-9618-1210

ÖZET

Bu makale, deprem kayıtlarını kullanarak köprü yapılarının sistem tanılaması için yeni bir yöntem sunmaktadır. Köprüler, genellikle yapısal elemanlarının geniş mesafelere yayılmasından ötürü, diğer yapılara nispeten yer hareketlerinin uzamsal değişkenliğine daha hassastırlar. Bu nedenle, özellikle temelleri değişik zemin türlerine oturan uzun ve çok kolonlu köprülerin simülasyonlarında kullanılacak nitelikte yer hareketi kayıtlarının ölçümü karmaşık bir süreçtir. Bilhassa hem eylemsizlik hem de kinematik Zemin-Yapı Etkileşimi etkilerinin yaygın olduğu durumlarda, köprü Temel Girdi Hareketlerinin doğrudan ölçümü mümkün olmayabilir. Bu çalışmada, uzamsal olarak seyrek bir şekilde ölçülmüş sismik yapı davranış kayıtlarını kullanarak eş zamanlı sistem ve girdi tanılamas sağlayan yeni bir yöntem önerilmektedir. Önerilen metodun teyiti ve gerçek ölçekte problemlere uygulanabilirliğini doğrulamak adına, yöntem Golden Gate Köprüsü'ne uygulanmış ve elde edilen sonuçlar mevcut veriler ile karşılaştırılmıştır.

Anahtar kelimeler

Golden Gate Köprüsü, Kuvvetli Yer Hareketi, Temel Giriş Hareketleri, Zemin-Yapı Etkileşimi

Öne Çıkanlar

* Köprü yapılarının sistem tanılaması için yeni yöntem

* Seyrek ölçülen deprem kaynaklı tepkileri kullanarak birleşik sistem-giriş tanımı çözümü

* Köprü Temel Giriş Hareketlerinin doğrudan ölçümü (TGH)
Makale

Araştırma Makalesi

Geliş: 18.07.2019

Düzeltme: 22.11 .2019

Kabul: 22.11.2019

Basım: 30.12.2019

DOI

doi.

Sorumlu yazar

Ertuğrul Taciroğlu

Eposta: etacir@g.ucla.edu

\section{Joint System-Input Identification of Bridge Structures}

Seyed Farid Ghahari ${ }^{1}$, Mehmet Çelebi ${ }^{2}$, Hamed Ebrahimian ${ }^{3}$, Barbaros Cetiner ${ }^{1}$ and Ertugrul Taciroglu ${ }^{1}$

${ }^{1}$ Department of Civil \& Environmental Engineering, University of California, Los Angeles

2 United States Geological Survey, Menlo Park, CA

${ }^{3}$ Department of Civil and Environmental Engineering at the University of Nevada, Reno (UNR)

ORCID: 0000-0002-3847-5277, 0000-0002-4769-7357, 0000-0003-1992-6033, 0000-0002-9726-8120, 0000-0001-9618-1210

\section{ABSTRACT}

This paper presents a novel framework for system identification of bridge structures using recorded earthquake data. Bridge structures are prone to spatial variability of ground motions because they extend over relatively long distances. So, input motion measurement is a challenging task, especially for long bridges with multiple piers. Moreover, direct measurement of the bridge Foundation Input Motions (FIMs) may not be possible due to both inertial and kinematic Soil-Structure Interaction (SSI) effects. In this study, we propose a joint system-input identification solution using sparsely measured earthquake-induced responses. We verify this method and its applicability for real scale problems using simulated data obtained from the Golden Gate Bridge.

Keywords

Golden Gate Bridge, Strong Ground Motion, Foundation Input Motions, Soil-Structure Interaction

Highlights

* Novel framework for system identification of bridge structures

* Joint system-input identification solution using sparsely measured earthquake-induced responses

* Direct measurement of the bridge Foundation Input Motions (FIMs)

\section{Manuscript}

Research Article

Received: 18.07.2019

Revised: 22.11.2019

Accepted: 22.11.2019

Printed: 30.12.2019

DOI

doi.

Corresponding Author

Ertugrul Taciroglu

Email: etacir@g.ucla.edu 


\section{GíRiş}

Her ne kadar köprü yapılarının deprem davranışlarını doğru olarak tahmin etmek için son derece ayrıntılı ve kesin Sonlu Elemanlar (SE) modelleri gerekli olsa da, yüksek hassaslıklı bir model yapısal davranışın doğru bir biçimde öngörümü için yeterli değildir. Günümüzde köprülerin yapısal davranışını yüksek kesinlikle hesaplamayı mümkün kılacak nitelikte hem ticari hem de açık kaynak kodlu yazılım paketleri mevcut olmakla beraber, doğru davranış tespitleri için gerekli fiziksel bağlamda hatasız ve tutarlı deprem girdi kayıtlarının uygulanabilmesi oldukça güçtür. Deprem yer hareketlerinin uzamsal değişkenliği göz önünde bulundurulduğunda bu sorun uzun köprü yapıları için daha da zorlu bir hale gelir (Zerva ve Zervas 2002). Mevcut uygulamada, Kaliforniya Eyaleti Ulaşım Dairesi Başkanlığı (Caltrans) şartnamelerinde de belirtildiği gibi, tek boyutlu zemin tepki analizleri kullanarak köprünün her bir ayağı için ayrı yer hareketi kaydı belirlenmesi suretiyle deprem kaynaklı yer sarsıntılarının uzamsal değişkenliğinin hesaba katılması yaygınca kullanılan yöntemdir. Bahsedilen zemin tepki analizi prosedürü, ana kaya seviyesinde oluşması beklenen sismik hareketi her bir ayağın bulunduğu yüzey noktasına mevcut geoteknik bilgilerin ışığında aktarılmasından oluşmaktadır. Kinematik Zemin-Yapı Etkileşimi (ZYE) etkilerinin varlığında, yapı davranışlarının doğru bir biçimde hesaplanabilmesi için, bu Serbest Saha Hareketlerinin $\left(\mathrm{SSH}^{1}\right)$ gerekli metotlar yoluyla Temel Girdi Hareketlerine (TGH) çevrilmesi şarttır (Şekil 1). Özetle, uzun köprü yapılarının, yapının bulunduğu alandaki ana kaya seviyesi yer hareketlerinin eş dağılımlı olduğu durumlarda bile, köprü ayaklarında farklı zemin sarsıntılarına maruz kalması olasıdır. Bahsedilen işlem birkaç önemli varsayıma dayanmaktadır. Tek boyutlu zemin tepki analizi, kesinliği belli durumlarda yetersiz kalan, deprem dalgalarının sadece düşey doğrultuda yayıldığı ve yatay deplasmanlara yol açtığı varsayımını benimsemektedir. Ana kaya seviyesi yer hareketlerini yüzey seviyesi deprem kayıtlarından tahmin etmek için kullanılan ters evrişim yöntemleri de çeşitli sayısal hatalara meydan vermektedir (ana kaya seviyesinde hesaplanan olağan dışı büyüklükteki yer hareketi kayıtları bu hatalara bir örnektir). SSH'lerin TGH'lere dönüştürülmesi başka bir önemli potansiyel hata kaynağıdır ve şu noktada söz konusu dönüştürmeyi gerçekleştirmek için tam anlamıyla doğrulanmış standart bir yaklaşım bulunmamaktadır.

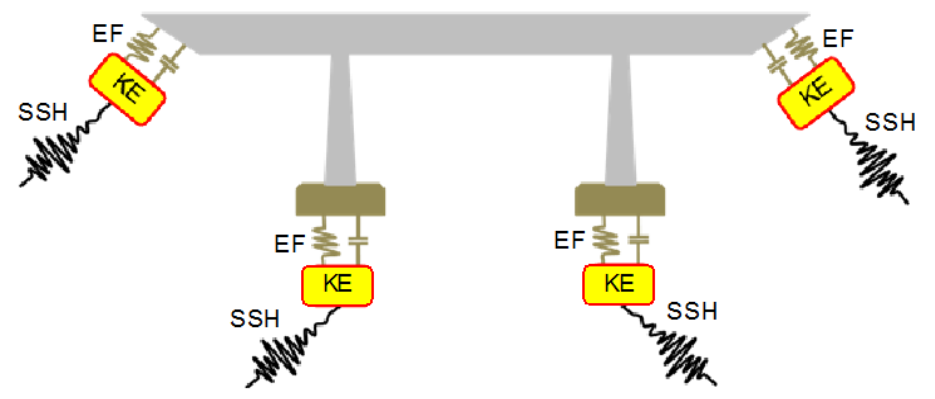

Şekil 1: Uzun bir köprü yapısının dinamik analiz modelinin şematik gösterimi (SSH: Serbest Saha Hareketleri, KE: Kinematik Etkileşim, EF: Empedans Fonksiyonu)

TGH'lerin kuvvetli yer hareketi sensörleri ile donatılmış köprülerden geri hesaplanması, deprem sırasında köprü yapılarında sarsıntıya sebep olan asıl yer hareketi girdilerini incelemek ve TGH öngörüsünde kullanılan yeni veya mevcut prosedürleri doğrulayabilmek (ya da reddetmek) için gerekli bir analiz kabiliyetidir. Bununla birlikte, köprü yapılarının mekanik özelliklerine ilaveten kolon temelleri ve kenar ayakları çevresindeki sınırların tanımlanmasındaki ek belirsizlikler nedeniyle, kaydedilen yapısal titreşim verilerinden TGH'leri tahmin etmek için alışılagelen ters

${ }^{1}$ Uluslarası literaturde "Free Field Motion (FFM)" olarak tanımlanır. 
evrişim yöntemleri kullanılamaz. Örneğin, Empedans Fonksiyonu (EF) (Wolf ve Deeks 2004) olarak adlandırılan zemin-temel ara yüzündeki zemin esneklik ve sönümleme davranışı büyük belirsizlikler içerir ve bu belirsizlikler deprem sırasında köprülerin maruz kaldığı TGH'lere yakınsak olmayan davranış tahminlerine neden olabilir. Bu sorunu çözmek için, bu çalışmada, deprem sırasında kaydedilen uzamsal olarak seyrek ölçülmüş sismik kayıtları kullanarak TGH tanımlaması yapan ve köprülerin belirsiz özelliklerini tanımlayabilen bir eş zamanlı sistem ve girdi yöntemi önerilmektedir. Önerilen prosedür, bina yapıları için Astroza ve diğ. (2017)'de geliştirilen sıralı Bayesçi model güncelleme yöntemini kullanır. Bu yöntemin genel temsili Şekil 2'de gösterilmekte ve detayları takip eden bölümde açıklanmaktadır. Kısaca, bu yöntemde, sistemin bilinmeyen değişken ve girdilerini içeren değişken vektörünün $(\psi)$ normal olasılık dağılımına bağlı kaldığı varsayılır ve elde edilen belirsizlik SE modeli kullanılarak sisteme aktarılır. Sonrasında, sensör ölçümleri ve hesaplanan $\psi$ değerleri arasındaki farklar vasıtasıyla, Bayes kuralını kullanarak, değişken vektörünün sonsal olasılık dağılımı hesaplanır. Bu işlem sensör kayıtlarındaki tüm zaman aralıkları taranmak üzere ardışık bir biçimde tekrarlanır.

Önerilen yöntemin büyük ölçekli bir yapıya uygulanması süreci ilk kez bu çalışmada sunulmaktadır. Bu maksatla, Golden Gate Köprüsü (GGK)'nün ayrıntılı bir SE modeli yaratılmış ve 2014 Güney Napa depreminde kaydedilen yapı tepkilerini kullanarak yapısal davranışı simüle edilmiştir. Önerilen eş zamanlı sistem ve girdi çözümü yönteminin kullanımını mümkün kılmak ve TGH'lere ek olarak belli başlı bilinmeyen yapısal parametreleri uzamsal olarak seyrek ölçülmüş yapı davranışları aracılığıyla tanılamak için tasarlanan çift paralel hesaplama çerçevesi de ayrıntılı bir biçimde anlatılmaktadır.

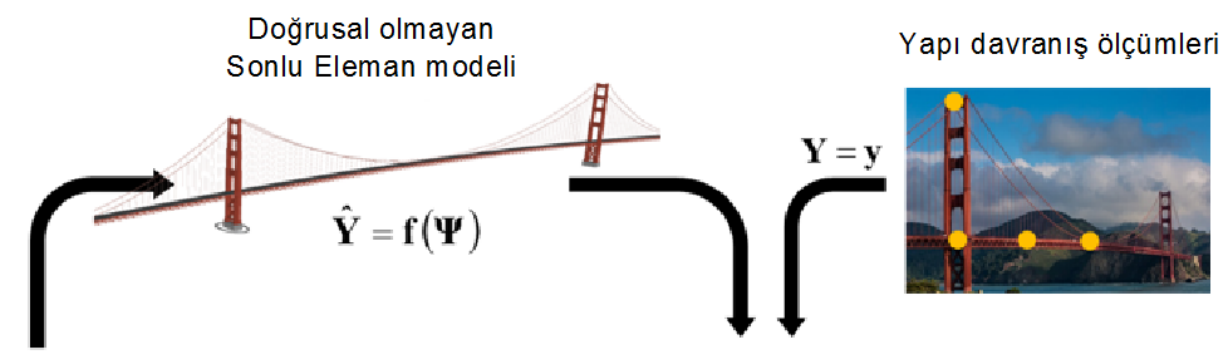

Önsel bilgi olasılık dağılımı

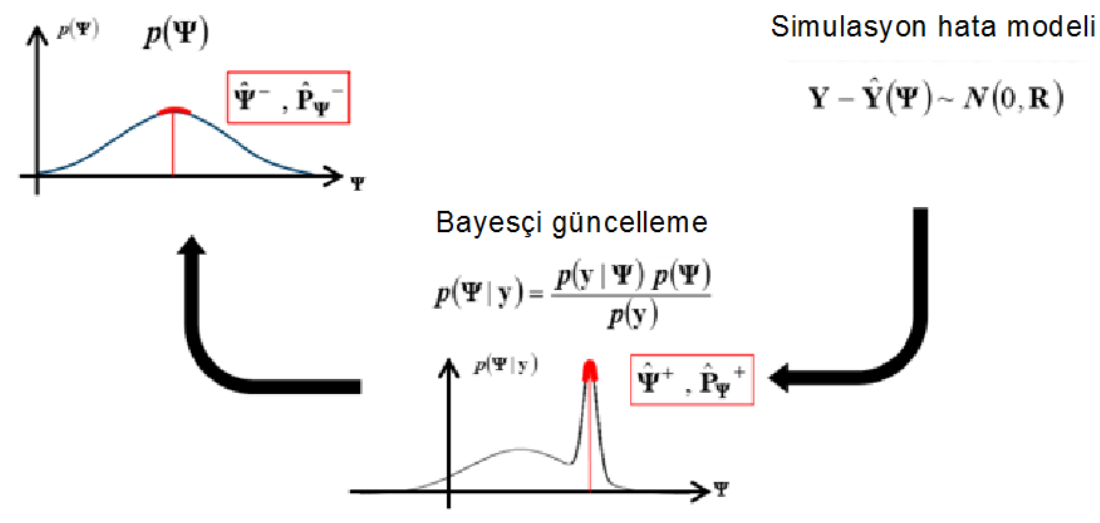

Şekil 2: Önerilen tanılama yönteminin genel temsili 


\section{TANILAMA YÖNTEMI}

Geliştirilen, Kokusuz Kalman Süzgeci yöntemine (Astroza ve diğ. 2017) dayanan, eş zamanlı sistem ve girdi çözümü yaklaşımı bu bölümde kısaca açıklanmaktadır. Bir köprü yapısının SE modelinin her bir zaman adımındaki çok mesnetli sismik davranışı model parametre vektörü $\boldsymbol{\theta}$, ve temel giriş hareket kayıtlarının, $\ddot{\boldsymbol{u}}_{1: i}^{g}$, doğrusal olmayan bir fonksiyonu olarak aşağıdaki gibi ifade edilebilir.

$$
\widehat{\boldsymbol{y}}_{i}=h_{i}\left(\boldsymbol{\theta}, \ddot{\boldsymbol{u}}_{1: i}^{g}\right)
$$

Burada $h_{i}($.$) SE modelinin 1. adımdan i$ numaralı adıma kadarki tüm dinamiklerini göz önünde bulundurarak zaman adımı $i$ için hesaplanan doğrusal olmayan tepki fonksiyonudur. Yapının ölçülen davranış vektörü $\boldsymbol{y}_{i}$, ve SE analizi yoluyla hesaplanan öngörülen davranış vektörü, $\hat{\boldsymbol{y}}_{i}$ arasındaki ilişki şu şekilde tanımlanabilir:

$$
\boldsymbol{v}_{i}\left(\boldsymbol{\theta}, \ddot{\boldsymbol{u}}_{1: i}^{g}\right)=\boldsymbol{y}_{i}-\widehat{\boldsymbol{y}}_{i}\left(\boldsymbol{\theta}, \ddot{\boldsymbol{u}}_{1: i}^{g}\right)
$$

Burada $v_{i} \in \mathrm{R}^{n_{y} \times 1}$ simülasyon hata vektörüdür ve yapının ölçülen ile $\mathrm{SE}$ analizi tarafından öngörülen davranışı arasındaki uyumsuzluğu ifade eder. Simülasyon hatası, model tanımlama sürecinde oluşabilecek hatalar ihmal edildiği sürece, sıfır ortalamalı Gauss gürültü vektörü, $\boldsymbol{v}_{i} \sim N(\mathbf{0}, \mathbf{R})$, olarak idealize edilebilir (Ebrahimian ve diğ. 2017). Bu tahmin probleminin ana hedefi $\boldsymbol{\psi}_{i}=\left[\boldsymbol{\theta}^{T}, \ddot{\boldsymbol{u}}_{1: i}^{g}{ }^{T}\right]^{T}$ bilinmeyen değişken vektörünün, ölçülen ve SE analizlerince öngörülen yapısal davranışlar arasındaki tutarsızlıkları olasılıksal anlamda en aza indirgemek suretiyle, hesaplanmasıdır. Problem yüksek derecede doğrusal olmayan süreçlerden meydana geldiğinden, bu çalışmada çözümleme verimliliğini artırmak amacı ile ardışık kestirim yaklaşımı benimsenmiştir. Bu yaklaşımda, kayıt zaman alanı, tahmin penceresi olarak da bilinen ardışık ve örtüşen zaman pencerelerine bölünmüştür. Bilinmeyen değişken vektör değerlerinin tespiti için hesaplamalar her zaman penceresi için ayrı olarak gerçekleştirilmiştir. $m$-inci tahmin penceresinin $t_{1}^{m}$ zaman adımından $t_{2}^{m}$ zaman adımına kadar belirtildiği durumda, bu tahmin penceresindeki bilinmeyen değişken vektörü $\boldsymbol{\psi}_{m}=\left[\boldsymbol{\theta}^{T}, \ddot{\boldsymbol{u}}_{t_{1}^{m}: t_{2}^{m}}^{g, m}\right]^{T}$ olarak tanımlanabilir. Bu tanımlamada $\boldsymbol{\psi}_{m} \in$ $\mathrm{R}^{\left(n_{\boldsymbol{\theta}}+t_{l} \times n_{\ddot{\boldsymbol{u}}} g\right) \times 1}, t_{l}=t_{2}^{m}-t_{1}^{m}$ tahmin pencere boyu ve $n_{\ddot{\boldsymbol{u}}^{g}}$ ise bilinmeyen temel giriş hareketi bileşen sayısına tekabül eder. Bilinmeyen değişken vektörü, $\boldsymbol{\psi}_{m}$, sadece sistem parametrelerinin çözümü için tanımlanan bir Kalman süzgeç yöntemi ile hesaplanmaktadır. Bu hesaplamalarda bilinmeyen değişken vektörü, evrimi, aynı zamanda rastgele yürüyüş olarak da bilinen, Gaussian Markov süreci ile nitelendirilen stokastik bir vektör olarak modellenebilir. Bu tanımlamaların ardından, durum denkleminin rastgele parametre vektörünün evrimini yönlendirdiği ve ölçüm denkleminin ölçülen ve SE tarafından öngörülen yapısal tepkiler arasındaki tutarsızlığa karşılık geldiği, bir durum-uzay modeli aşağıdaki tanımlamalara göre oluşturulur (Haykin 2001).

$$
\begin{gathered}
\boldsymbol{\psi}_{m, k+1}=\boldsymbol{\psi}_{m, k}+\boldsymbol{\gamma}_{m, k} \\
\boldsymbol{y}_{t_{1}^{m}: t_{2}^{m}}=\widehat{\boldsymbol{y}}_{t_{1}^{m}: t_{2}^{m}, k+1}\left(\boldsymbol{\psi}_{m, k+1}\right)+\boldsymbol{v}_{t_{1}^{m}: t_{2}^{m}, k+1}
\end{gathered}
$$

Burada $\boldsymbol{\gamma}_{m, k} \sim N(\mathbf{0}, \mathbf{Q}), \boldsymbol{v}_{t_{1}^{m}: t_{2}^{m}, k+1} \sim N(\mathbf{0}, \widetilde{\mathbf{R}})$ ve $\widetilde{\mathbf{R}} \in \mathrm{R}^{\left(t_{l} \times n_{y}\right) \times\left(t_{l} \times n_{y}\right)}$ blok köşegenleri simülasyon hatası kovaryans matrisi R'den oluşan bir blok köşegen matristir. (3) ve (4) numaralı 
denklemlerdeki $k$ sembolü iterasyon sayısını belirtir. Şu ana kadarki tanımlamalardan da görülebileceği gibi, her bir zaman penceresindeki hesaplama süreci yinelemelidir. Diğer bir deyişle, bilinmeyen değişken vektörünün ortalama vektörü ve kovaryans matrisi, ölçülen ve hesaplanan yapısal davranışlarının zaman tanım alanında sergilediği tutarsızlıklar ışığında, yineli bir biçimde güncellenir.

Her yinelemede bilinmeyen değişken vektörünün güncellenmesi için Kokusuz Kalman Süzgeç yöntemi kullanılmaktadır. Bu yöntemde, doğrusal olmayan SE modeli, sigma noktaları $\left(\boldsymbol{\vartheta}^{j}\right)$ olarak adlandırılan, bilinmeyen değişken vektörünün deterministik bir biçimde belirlenen bir alt kümesinin tüm noktalarında değerlendirilir. Sigma noktaları, önsel ortalama dağılımı $\widehat{\boldsymbol{\psi}}^{-}$'nin etrafında seçilir. Bu çalışmada, $2 n_{\psi}+1$ sayıda sigma noktasını $\left(j=1,2, \ldots, 2 n_{\psi}+1\right)$ baz alan bir Ölçeklendirilmiş Kokusuz Dönüşüm kullanılmıştır. Burada $n_{\psi}$ genişletilmiş parametre vektörünün boyutunu belirtir. SE analizlerince öngörülen yapısal davranışların ortalama vektörü, kovaryans matrisi ve $\boldsymbol{\psi}$ ile $\boldsymbol{y}^{\prime}$ nin çapraz kovaryans matrisleri, sırasıyla aşağıda belirtilen ağırıklı örnekleme yöntemi kullanılarak hesaplanmaktadır.

$$
\begin{gathered}
\overline{\boldsymbol{y}}=\sum_{j=1}^{2 n_{\psi^{+1}}} W_{m}^{j} \widehat{\boldsymbol{y}}_{i}\left(\boldsymbol{\vartheta}^{j}\right) \\
\widehat{\mathbf{P}}_{\boldsymbol{y} \boldsymbol{y}}=\sum_{j=1}^{2 n_{\psi^{+1}}} W_{e}^{j}\left[\widehat{\boldsymbol{y}}_{i}\left(\boldsymbol{\vartheta}^{j}\right)-\overline{\boldsymbol{y}}\right]\left[\widehat{\boldsymbol{y}}_{i}\left(\boldsymbol{\vartheta}^{j}\right)-\overline{\boldsymbol{y}}\right]^{T}+\mathbf{R} \\
\widehat{\mathbf{P}}_{\boldsymbol{\psi} \boldsymbol{y}}=\sum_{j=1}^{2 n_{\psi^{+1}}} W_{e}^{j}\left[\boldsymbol{\vartheta}^{j}-\widehat{\boldsymbol{\psi}}^{-}\right]\left[\widehat{\boldsymbol{y}}_{i}\left(\boldsymbol{\vartheta}^{j}\right)-\overline{\boldsymbol{y}}\right]^{T}
\end{gathered}
$$

Bu denklemlerde $W_{m}^{j}$ ve $W_{e}^{j}$ ağırık katsayılarını belirtir (Julier ve Uhımann 1997). Bu noktada, her iterasyonda, Kokusuz Kalman Süzgeç tahmin düzeltme sürecinden faydalanarak sonsal parametre ortalama vektörü $\left(\widehat{\psi}_{m, k+1}^{+}\right)$ve kovaryans matrisi $\left(\widehat{\mathrm{P}}_{\psi, m, k+1}^{+}\right)$hesaplanabilir. Yukarıda tarif edilen tanılama yönteminin algoritmik bir özeti Tablo 1'de verilmiştir. 
Tablo 1: Model parametrelerinin ve TGH zaman geçmişinin birleşik tahmini için tanımlama algoritması

1. Tahmin penceresi uzunluğu $t_{l}$ 'nin ve her bir tahmin penceresinin başlangıç ve bitiş noktalarının ayarlanması.

2. Bilinmeyen değişken vektörünün ortalama vektörü ve kovaryans matrisinin başlangıç değerlerinin aşağıdaki gibi kurulması.

$$
\widehat{\boldsymbol{\psi}}_{0}^{+}=\left[\widehat{\boldsymbol{\theta}}_{0}{ }^{T}, \ddot{\boldsymbol{u}}_{t_{1}^{0}: t_{2}^{0}}^{g{ }^{T}}\right]^{T} \text {, and } \mathbf{P}_{\boldsymbol{\psi}, 0}^{+}=\left[\begin{array}{cc}
\widehat{\mathbf{P}}_{\boldsymbol{\theta} \boldsymbol{\theta}, 0} & \mathbf{0} \\
\mathbf{0} & \widehat{\mathbf{P}}_{\ddot{\boldsymbol{u}}} g, 0
\end{array}\right]
$$

3. Süreç gürültü kovaryans matrisi $\mathbf{Q}$ ve simülasyon hata kovaryans matrisi R'nin tanımlanması.

$\widetilde{\mathbf{R}}$ matrisinin belirlenmesi.

4. $m$ 'inci zaman penceresi için:

4.1. Son zaman penceresine ait bilinmeyen parametre vektörünün ortalama vektörü ve kovaryans matrisinin sonsal tahminlerinin $\left(\widehat{\boldsymbol{\psi}}^{+}{ }_{m-1}\right.$ ve $\left.\mathbf{P}_{\boldsymbol{\psi}, m-1}^{+}\right)$alınması. $\widehat{\boldsymbol{\psi}}^{+}{ }_{m-1}$ ve $\mathbf{P}_{\boldsymbol{\psi}, m-1}^{+}$'ye göre $\widehat{\boldsymbol{\psi}}^{+}{ }_{m, 0}$ ve $\mathbf{P}_{\psi, m, 0}^{+}$'nin belirlenmesi.

4.2. $k=1,2, \ldots$ için iterasyon adımları:

a. $\widehat{\boldsymbol{\psi}}^{-}{ }_{m, \mathrm{k}+1}=\widehat{\boldsymbol{\psi}}^{+}{ }_{m, \mathrm{k}}, \mathbf{P}_{\boldsymbol{\psi}, m, k+1}^{-}=\mathbf{P}_{\boldsymbol{\psi}, m, k}^{+}+\mathbf{Q}$ olarak tanımlanması.

b. Sigma noktalarının oluşturulması. SE modelinin $2 n_{\psi}+1$ sigma noktası için analizi. Denklem (5-7)'yi kullanılarak $\overline{\boldsymbol{y}}, \widehat{\mathbf{P}}_{\boldsymbol{y} \boldsymbol{y}}$ ve $\widehat{\mathbf{P}}_{\boldsymbol{\psi} \boldsymbol{y}}$ 'nin türetilmesi.

c. Kalman kazanç matrisi $\left(\mathbf{K}=\widehat{\mathbf{P}}_{\boldsymbol{\psi} y}\left(\widehat{\mathbf{P}}_{\boldsymbol{y} \boldsymbol{y}}\right)^{-1}\right)$ 'nin hesaplanması.

d. Bilinmeyen değişken vektörünün ortalama vektörü ve kovaryans matrisinin düzeltilmiş tahminlerinin aşağıda belirtildiği gibi bulunması.

$$
\widehat{\boldsymbol{\psi}}^{+}{ }_{m, \mathrm{k}+1}=\widehat{\boldsymbol{\psi}}^{-}{ }_{m, \mathrm{k}+1}+\mathbf{K}\left(\boldsymbol{y}_{t_{1}^{m}: t_{2}^{m}}-\overline{\boldsymbol{y}}\right), \mathbf{P}_{\boldsymbol{\psi}, m, k+1}^{+}=\mathbf{P}_{\boldsymbol{\psi}, m, k+1}^{-}-\mathbf{K}\left(\widehat{\mathbf{P}}_{\boldsymbol{y} \boldsymbol{y}}+\widetilde{\mathbf{R}}\right) \mathbf{K}^{T}
$$

e. Yakınsama kontrolünün yapılması: Eğer $\left|\widehat{\boldsymbol{\psi}}^{+}{ }_{m, k+1}-\widehat{\boldsymbol{\psi}}^{+}{ }_{m, k}\right|<0.02 \times \widehat{\boldsymbol{\psi}}^{+}{ }_{m, k-1}$ veya $k+1>10$ ise sonraki tahmin penceresine geç ( $m=m+1$ ve 4 'üncü adıma git). Değilse, mevcut tahmin penceresinde yineleme yap ( $k=k+1$ ve 4.2 'nci adıma git).

\section{YÖNTEMIN DOĞRULANMASI}

Bu bölümde, önerilen çıktı bazlı tanımlama yöntemini doğrulamak için GGK'den elde edilen temsili veriler kullanılmaktadır. GGK'nün bu uygulama için seçilmesindeki sebep önerilen yöntemin büyük ölçekli gerçek köprülere uygulanabilirliğini kanıtlamaktır. GGK (Şekil 3), San Francisco şehrini Marin İlçesine bağlayan, Golden Gate boğazı üzerine kurulu bir asma köprü sisteminden oluşmaktadır. 1964 yılına kadar GGK dünyanın en uzun ana açıklığına sahip asma köprüsü yapısı unvanını elinde tutmuştur ve günümüzde Amerikan İnşaat Mühendisleri Derneği (ASCE) tarafından modern dünyanın harikalarından biri olarak kabul edilmektedir. 


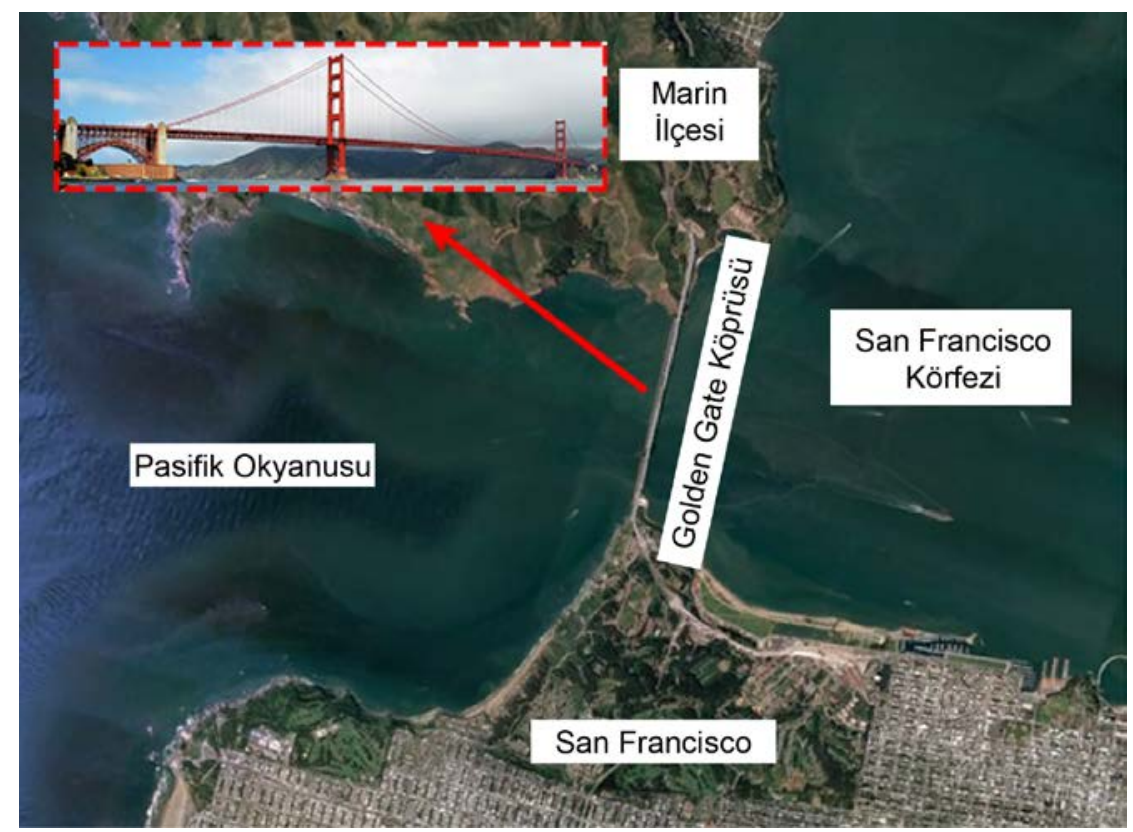

Şekil 3: Golden Gate Köprüsü (GGK)

GGK'nün inşası 28 Mayıs 1937 'de tamamlanmış ve bu tarih itibariyle köprü trafiğe açılmıştır (Strauss ve Paine 1938). Köprünün kenar ayakları arasındaki toplam mesafe $2737 \mathrm{~m}$, diğer açıklık ve yükseklik bilgileri de Şekil 4'te belirtildiği gibidir. Ketchum ve Seim (1990)'da köprünün yapısal sistemi hakkında derlenen bilgiler burada kısaca özetlenmektedir (Sistemin elemanlarının geometrik ve mekanik özellikleri Abdel-Ghaffar ve Scanlan (1985a,b) gibi birçok kaynakta kapsamlı biçimde yer aldığından burada tartışılmamıştır). Bir asma köprü yapısı olarak GGK farklı tipte sistemlerin birleşiminden oluşmaktadır. Bu sistemlerin her biri Şekil 5'te gösterilmektedir. Yaklaşma viyadükleri çelik kemer, kafes ve kiriş sistemlerinden oluşmaktadır. Ankraj blokları (güney kısım bloğu Şekil 5 'te gösterilmemiştir), payandalar ve pilonlar betonarme; kuleler, tabliye taşıyıcı sistemi ve kablolar (ana ve askı kabloları) ise çelikten yapılmıştır. Kulelerin temeli doğrudan anakaya üzerinde yer alır. Aslen betonarme olarak inşa edilen tabliye, 1980'lerde, orta bölümü ortotropik çelik levhalar, kaldııım bölümleri betonarme ve her 8 metrede bir kiriş elemanı ile desteklenecek şekilde yenilenmiştir. Bu kirişler köprünün her iki tarafında takviye kafeslerine bağlıdır. Asıl yapıda bu takviye kafesleri yalnızca üst seviyede yatay takviyeler ile birbirine bağlanmıştır. Daha sonra 1950'lerde, tabliye taşıyıcı sisteminin burulma ve bükülme potansiyelini azaltmak amacıyla taşıyıcı sistemin alt seviyesine de yatay takviyeler eklenerek sistem kapalı kesite dönüştürülmüştür. 1970'lerde, bahsedilen takviye sistemi, her 15 metrede bir köprünün iki tarafına yerleştirilen askı kablolarıyla taşınır hale gelmiştir. Köprünün ana açıklığı her iki uçta kulelere enine ve düşey doğrultularda sabitlenmiştir. Fakat boyuna doğrultuda ana açıklık sınırlı oranda serbest hareket imkânına sahiptir ve her iki açıklık uç noktasında mafsallar yardımıyla serbest biçimde dönmeye uygun bir biçimde tasarlanmıştır. 
Ghahari et al. / Turkish Journal of Earthquake Research 1 (2), 98-122, December 2019

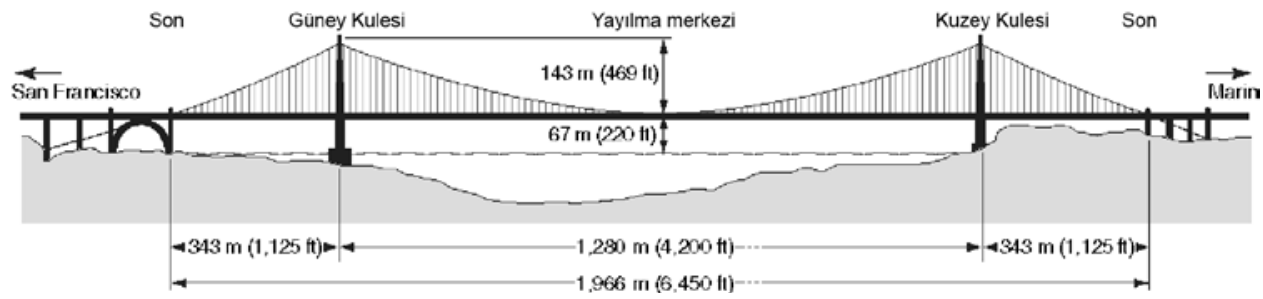

Şekil 4: Köprü boyutları (Çelebi 2012).

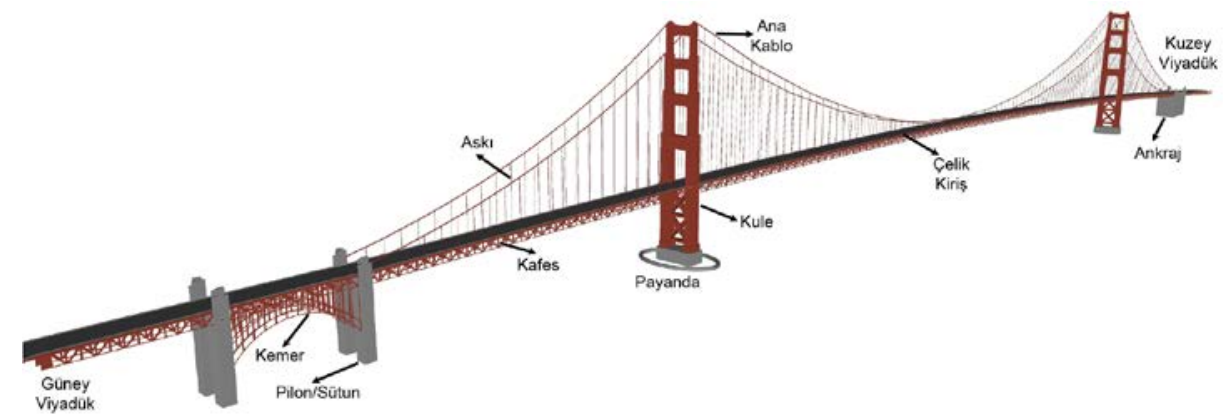

Şekil 5: GGK'nin çeşitli parçaları (3 boyutlu model SketchUp Warehouse'dan alınmıştır)

Her ne kadar GGK, yukarıda belirtildiği gibi, 1989 Loma Prieta depremine kadarki süreçte birkaç güçlendirme çalışması geçirmiş olsa da deprem sonrasında gerçekleştirilen yapısal değişikliler köprünün davranışında en büyük rolü oynamaktadır. Loma Prieta depremi akabininde Otoyol ve Ulaşım Bölgesinin ${ }^{2}$ çalışmaları sonucu kuleler ve tabliye takviye kafeslerinin arasına sönümleyicilerin yerleştirilmesi, köprü payandalarının takviye edilmesi ve kule tepelerindeki kablo desteklerinin güçlendirilmesi de dâhil olmak üzere yapıda bir dizi büyük çaplı güçlendirme çalışmasının gerekli olduğu anlaşılmıştır (Ingham ve diğ. 1995). Gerekli güçlendirmelerin yerine getirilmesi süreci 1997 yılında başlamıştır ve başlangıçta 2012'de sona ereceği tahmin edilmiş olsada, daha sonra proje tamamlama tarihinin birkaç kez değiştirilmesi sonrası, çalışmalarının 2021 yılında bitirilmesi öngörülmektedir.

\section{1) Sismik Hareket Sensörleri}

GGK'ya sismik sensör yerleştirilmesi işlemi ilk olarak 1992 yılında Karayolu ve Ulaştırma Bölgesi, CSMIP ve bir danışma kurulunun ortak çabası ile planlanmıştır (Shakal ve diğ. 1995). Köprüye 1995'te (güçlendirme öncesinde) 72 ivme-ölçer (15'i kuzey viyadüğe ve ankraj yuvası içine, 33'ü asma köprü kesimine, 22'si Fort Arch'a, güney viyadüğe ve ankraj yuvası içine, 3'ü köprünün güneyinde zemin kotuna, 3'ü güney viyadük altında geoteknik düşey ağ olarak) ve 4 göreli yer değiştirme sensörü yerleştirilmiştir (Huang ve diğ. 2013). Birinci güçlendirme fazının tamamlanmasından sonra, kuzey viyadüğe ve ankraj yuvasının içine 18 sensör yerleştirilmiş ve kuzey viyadük yakınına ise 6 sensörden oluşan ek bir geoteknik düşey ağ kurulmuştur. Son olarak ikinci güçlendirme fazı tamamlandıktan sonra mevcut ekipmana 22 sensör daha eklenmiştir. Sensörlerin yapının asma köprü kısmı üzerindeki güncel konumları Şekil 6'da gösterilmiştir.

21928 yılında kurulan Kaliforniya (A.B.D.) eyaletine bağıı özel bir bölgedir. 
Ghahari et al. / Turkish Journal of Earthquake Research 1 (2), 98-122, December 2019

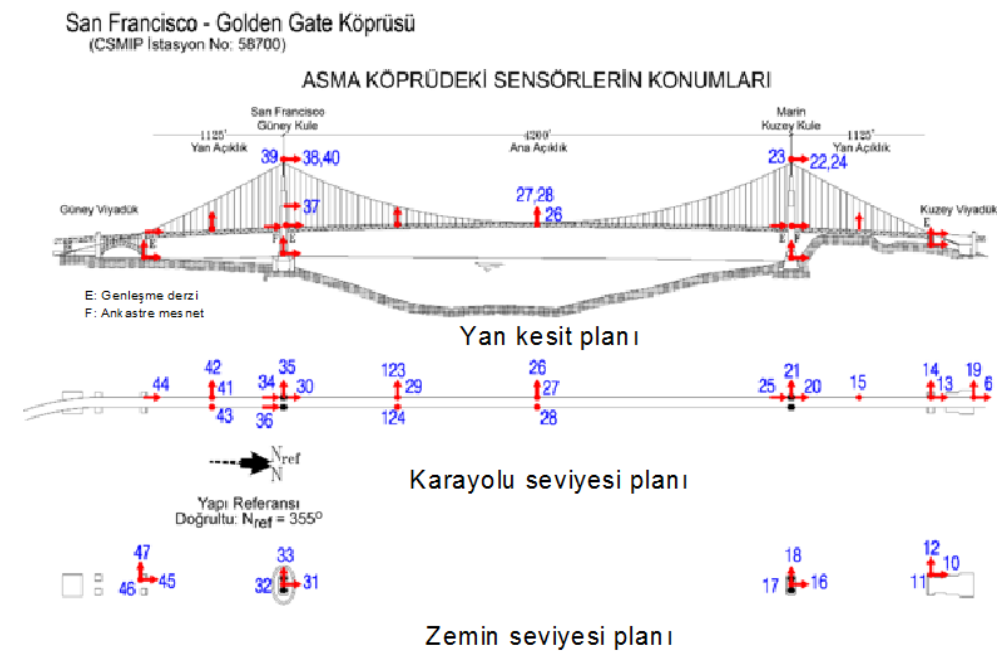

Şekil 6: Golden Gate Köprüsünün asma köprü kısmındaki kuvvetli yer hareketi sensörlerinin konumları

(CESMD 2017)

\section{2) Önceki Çalışmalar}

GGK, inşasından bu yana birçok çalışmanın konusu olmuştur. GGK'nın titreşim esaslı tanılanması üzerine yapılan en eski çalışma, 1947 yılında, Nishkian (1947)'ın olağan trafik yükleri altında köprü tabliyesinin düşey hareketinin ölçülmesi amaçlı gerçekleştirdiği tetkiklerden oluşmaktadır. Sonrasında, daha yüksek kesinlikli sensörler kullanılarak benzer ölçümlerin ortaya konduğu, buna ek olarak gerçek veriler ve model tahminlerinin karşılaştırdığı bir çift çalışma yerine getirilmiştir (Vincent 1962, Vincent ve Labse 1962). Vincent'ın söz konusu çalışmalarında mekanik (asılı kütle tipi) ivme-ölçerleriyle 15 yıllık bir zaman aralığında kaydedilen veriler kullanılmış ve köprü tabliyesinin birinci asimetrik, birinci ve ikinci simetrik düşey doğal frekansları sırasıyla 0.095, 0.125, $0.158 \mathrm{~Hz}$ olarak saptanmıştır. Buna ilaveten köprü burulma frekansı da $0.20 \mathrm{~Hz}$ olarak belirlenmiştir. Köprü üzerine hem sistem tanılama konusunda hem de diğer uygulamalar üzerine yapılan çalışmalarda 90'lı yıllardan itibaren belirgin bir artış gerçekleşmiştir. Tanaka ve Davenport (1983), Vincent (1962) tarafından kullanılan verileri yeniden incelemişler, köprünün deneysel gerili bant modelini ${ }^{3}$ laboratuvar ortamında rüzgâr türbülansı altında test etmiş ve düşük rüzgâr hızları için köprünün birinci asimetrik modunun titreşme davranışına hâkim olduğu sonucuna varmışlardır. Abdel-Ghaffar ve Scanlan $(1985 a, b)$, olağan titreşim verilerinden köprünün doğal frekansları, mod şekillerini ve sönüm oranlarını belirlemek için yapı üzerine kapsamlı deneysel araştırmalar yerine getirmiş; doğal frekans tanımlama işlemi için spektral pik seçim, mod şekli tanımlaması için çapraz spektrum analizi ve sönme oranı tahmini için yarı-güç bant genişliği yöntemlerini kullanmışlardır. Köprünün 0 ile $1.5 \mathrm{~Hz}$ frekans aralığında yer alan 20 düşey, 18 burulma, 33 yanal ve 20 boyuna modunu; 0 ile $5.0 \mathrm{~Hz}$ frekans aralığındaki 20 boyuna, 15 burulma ve kulelerin 11 yanal modunu tanımlayabilmişlerdir.

Pakzad ve diğ. (2008) ölçeklenebilir bir kablosuz sensör ağı tasarlamış ve kurmuş, sonrasında bu ağı kullanarak 2006 yazında topladıkları olağan titreşim verileri aracılıyla GGK'nün modal tanılamasını gerçekleştirmiştir. Analizlerini $5 \mathrm{~Hz}$ 'in altındaki modlarla sınırlandırmışlardır. Kablosuz sensör ağı kullandıklarından çeşitli alet dizilimleri ile titreşim ölçümleri tatbik edebilmişlerdir. Bu çalışma birçok önemli bulguya olanak vermiştir, bunlardan bir tanesi bu kadar

${ }^{3}$ Uluslarası literaturde "taut-strip model" olarak tanımlanır. 
Ghahari et al. / Turkish Journal of Earthquake Research 1 (2), 98-122, December 2019

büyük ve esnek bir yapı için ölçüm nokta sayısının az olması durumunda tanılamanın uzamsal örtüşme etkilerine maruz kalabileceğinin açıkça anlaşıllabilmiş olmasıdır ${ }^{4}$. Elde ettikleri bulgulara göre birinci düşey, enine ve burulma modlarının tamamının asimetrik olduğu ve sırasıyla 0.106, 0.228 ve $0.230 \mathrm{~Hz}$ frekanslarına sahip olduğu belirlenmiştir (Pakzad ve Fenves 2009). Bu değerli veri seti daha sonra bazı tanılama yöntemlerinin kontrolü ve doğrulanması amacı ile farklı çalışmalarda kullanılmıştır. Örneğin, Pakzad ve diğ. (2011)'nin bu veri seti aracılığıyla yayılı modal tanılama yaklaşımını doğrulaması mümkün olmuştur. Chang ve Pakzad (2013), aynı verileri kullanarak, geliştirdikleri iyileştirilmiş Doğal Uyarım Tekniği (NExT)'ni doğrulayabilmiştir. Ayrıca 2014 yılında aynı veriler Matarazzo ve Pakzad (2014) tarafından yalancı mobil algılama verisi oluşturma tekniği ${ }^{5}$ aracılığıyla çoğaltılmış ve beklenti maksimizasyonu ile yapısal tanılama (STRIDE) (Matarazzo ve Pakzad 2016) yöntemi kullanılarak GGK'nün olağan titreşim verilerinden modal özellikleri belirlenmiştir. Bu şekilde elde edilen sonuçlar Pakzad ve Fenves (2009) çalışmasındaki gözlemlerdekine benzer kesinlik değerleri göstermiştir.

2012 yılında, Çelebi (2012) GGK hakkında kapsamlı bir çalışma yapmış ve üç düşük şiddetli depremde kaydedilen verileri analiz etmiştir. Çalışmasında Bendat ve Piersol (1993) 'da bahsi geçen çıktı bazlı tanılama için spektral analiz yöntemi ve dışsal girdili otoregresif (ARX) (Ljung 1987) girdi-çıktı tanılama tekniği kullanılmıştır. Bu çalışma, modal özelliklerin deprem kayıtlarından tanımlandığı ilk çalışmadır ve $0.05 \mathrm{~Hz}$ 'in altındaki ve $50 \mathrm{~Hz}$ 'in üstündeki frekansların filtrelenmesi suretiyle gerçekleştirilmiştir. Bu çalışma bize çok önemli bilgiler sunsa da mükemmel değildir. ARX girdi-çıktı tanılama tekniği ile büyük ölçekli köprü yapıların davranışlarının belirlenmesinde önemli bir değişken olan, çok mesnetli sismik davranış hesaplamalara dâhil edilememektedir. Çok mesnetli sismik davranışın önemini daha net bir biçimde görebilmek için, 2014 Güney Napa depremi sırasında GGK'de kaydedilen temel seviyesi yer hareketleri arasındaki çapraz korelasyon indeksi (Bendat ve Piersol 1993) hesaplanabilir. Eylemsizlik yapı-zemin etkisinin önemsiz olduğu ve tüm köprü ayaklarının benzer sarsıntı hareketlerine maruz kaldığı durumlarda çapraz korelasyon değerinin 1'e çok yakın bir değer olması, yalnızca piklerin varış sürelerinde değişikliler gözlenmesi gerekmektedir. Şekil 7, dört köprü payandasındaki her bir enine sarsıntı kanalı CH47, CH33, CH18, CH12 (bkz. Şekil 6) için hesaplanan çapraz kovaryans indeksinin zaman gecikmesi değerlerine göre değişimini göstermektedir. Şekilde çapraz korelasyon eğrilerinin pik değerleri düşey kesikli çizgiler ile işaretlenmiş ve bu pik noktalarına karşılık gelen zaman gecikmelerinin mutlak değerleri her bir pik noktanın sağında belirtilmiştir. Görüldüğü üzere tüm kanal çiftleri arasında hesaplanan pik korelasyon değerleri oldukça düşüktür ve kayda değer ölçüde bağdaşmazlık göstermektedir (Kiureghian 1996).

Bunlara ek olarak, eş dağılımlı yer sarsıntısı varsayımı altında dahi, alışılmış girdi-çıktı tanılama teknikleri sadece deprem hareketi girdi noktaları ve kayıt cihazlarının bulunduğu yapısal davranış çıktı noktaları arasındaki modal özellikleri tanılamaya olanak sağlar. Bu yöntemler, zemin-yapı sınırlarında gözlemlenen zemin esnekliği gibi etkenleri inmal ederler. Bu çalışmada önerilen yöntem ise, tüm bu kısıtlamaları ortadan kaldırmak yoluyla, çok mesnetli sismik davranışın önemli olduğu köprü yapılarının deprem verilerinin kullanılmasıyla yapısal tanılaması doğrultusunda önemli bir adımdır.

\footnotetext{
${ }^{4}$ Bu sonuç, söz konusu çalışmanın net bulgusu değildir ve Pakzad ve diğ. (2008)'deki sonuçlara istinaden bu makalenin yazarlarının vardıkları görüşleri yansıtmaktadır. Ayrıca, uzamsal örtüşme ifadesi sinyal işleme alanında yaygın kullanım gören bir terim değildir.

${ }_{5}^{5}$ Yalancı mobil algılama verileri, mobil sensör ağının konuşlandırılmadığı noktalarda sentetik olarak elde edilen veri türüne verilen isimdir. Yalancı mobil algılama verileri, konuşlandırılmış mobil sensörlerin düzen planı bilindiği sürece, doğrudan sabit bir sensöre ait veri matrisinden türetilir. 
Ghahari et al. / Turkish Journal of Earthquake Research 1 (2), 98-122, December 2019
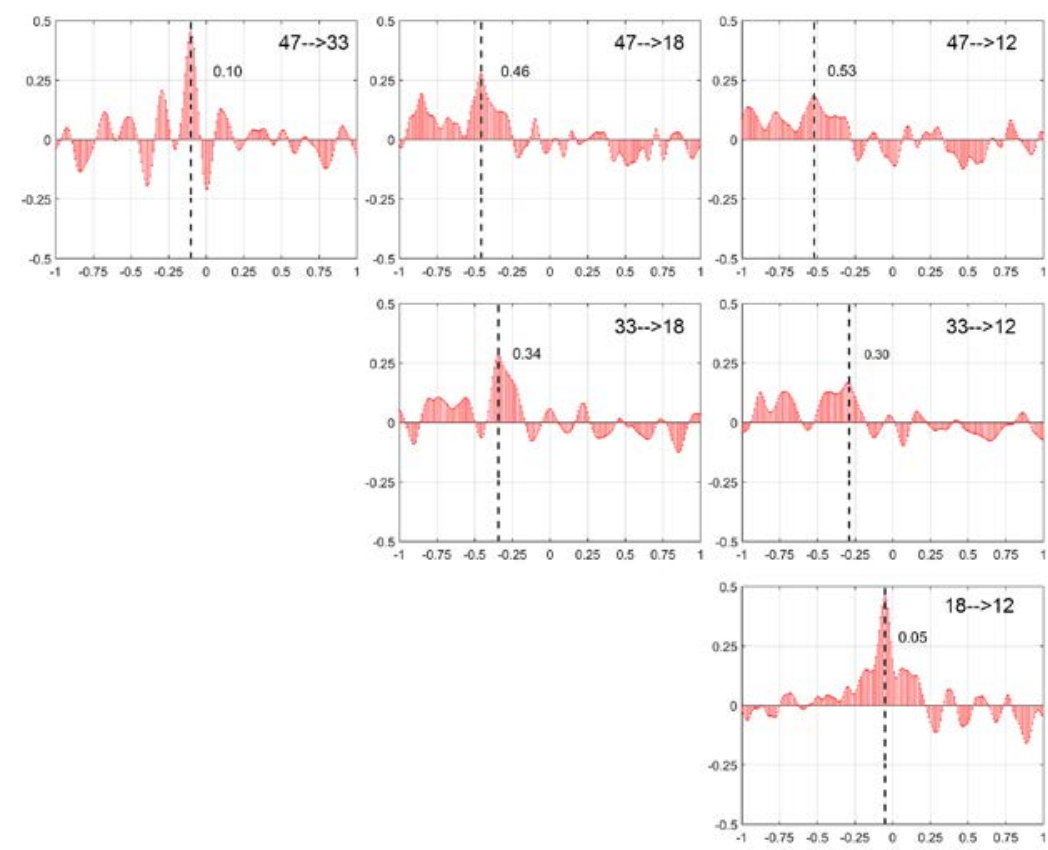

Şekil 7: GGK'nün temel seviyesindeki enine yönde ivme ölçme kanalları arasında 2014 Güney Napa depremi için gözlemlenen çapraz korelasyon eğrileri. Yatay eksenler saniye cinsinden zaman gecikme, düşey eksenler ise çapraz korelasyon indeks değerlerini belirtir.

\section{3) Sonlu Eleman Modeli}

Yazarların bilgisine göre GGK ile ilgili ilk sayısal çalışma 1976 yılında yapılmış; bu çalışma için köprünün dinamik davranışını boyuna-düşey ve enine-burulma yönlerinde incelemek için sırasıyla doğrusal 2 boyutlu (278 düğümlü) ve 3 boyutlu (120 düğümlü) modeller oluşturulmuştur (Baron ve diğ. 1976). Her iki modelde, zemin-yapı etkileşimini göz ardı ederek, kule ayaklarının zemine sabitlenmesi yoluyla, statik, özdeğer ve zaman tanım alanı analizleri yapılmıştır. Modeller hem eş dağılımlı hem de çok mesnetli yer hareketi sarsıntıları altında incelenmiştir. Ancak, çok mesnetli sismik davranışın temsilinde sadece deprem etkisinin her bir köprü ayağına farklı zamanlarda varışından kaynaklanan etkiler göz önünde bulundurulmuş, zemin kaynaklı etkiler ihmal edilmiştir. Abdel-Ghaffar (1976), asma köprülerin dinamik davranışlarının incelenmesi anlamında öncü çalışmalar gerçekleştirmiştir. GGK'nü çok mesnetli sismik davranış altında analiz etmek için, frekans tanım alanında rasgele titreşim yaklaşımını kullanarak, köprünün deprem kaynaklı (düşey ve boyuna titreşimlerden ötürü oluşan) düşey ve yanal (Abdel-Ghaffar ve Rubin 1983a,b; AbdelGhaffar ve Stringfellow 1984a,b) yapısal davranışlarını modellemiştir. Daha sonra Abdel-Ghaffar tarafından geliştirilen ve GGK'ne dair çeşitli çalışmalarda (Abdel-Ghaffar ve Scanlan 1985a,b) kullanılan 2 boyutlu doğrusallaştırılmış sonlu eleman modelleri, 193 hareketli düğüme sahip 283 kiriş elemanı ve 1146 serbestlik derecesinden oluşmaktadır. Kabloların eksenel gerilme etkileri, sistemin elastisite rijitlik matrisine bir geometrik rijitlik matrisinin eklenmesiyle, dâhil edilmiştir (Abdel-Ghaffar ve diğ. 1985). Bu modeller aracılıyla hesaplanan temel mod şekilleri ve doğal frekans değerlerinin deneysel ölçümler ile oldukça uyumlu olduğu gözlenmiş, Abdel-Ghaffar'e ait daha sade bir biçimde tanımlanmış 2 boyutlu modellerin Baron ve diğ. (1976) tarafından geliştirilen 3 boyutlu model kadar hassas çalıştığı gösterilmiştir.

Daha önce de belirtildiği gibi 1989 Loma Prieta depreminden sonra sismik değerlendirme ve olası güçlendirme gereksinimlerinin belirlenmesi amacıyla GGK'nde bir dizi çalışma 
gerçekleştirilmiştir. Otoyol ve Ulaşım Bölgesi yönetimi bu değerlendirme çalışmaları için T.Y. Lin International (TYLI) şirketini ve alt danışmanlar olarak Imbsen ve Associates Inc. (IAI) ile Geospectra Inc.'I görevlendirmiştir (Seim ve Rodriguez 1993). TYLI bu değerlendirmelerinde aslen daha önceki toplu taşıma fizibilite çalışmaları için geliştirilmiş oldukları 3 boyutlu modeli kullanmışlardır (Seim ve Ketchum 1990). Bu model, 4775 düğüm noktasını birbirine bağlayan 9933 çerçeve elemanın süper-eleman formülasyonu ile toplam serbestlik derecesi 4000 civarına indirgenmesiyle elde edilen bir sistemden oluşmaktadır (Ketchum ve Seim 1990). Bu modelin analizinde, Abdel-Ghaffar (1976)'ın çalışmasına benzer şekilde, dinamik yüklerin ölü yük konfigürasyonunda değişikliklere yol açarak yapısal davranışı etkilediği kabul edilmiş, diğer bir deyişle dinamik analiz problemi farklı ölü yük durumlarına göre çözümlemelerle doğrusallaştırılmıştır. Ayrıca, doğrusal olmayan geometri etkileri geometrik rijitlik matrisleri kullanılarak hesaplamalara dâhil edilmiştir. Bu genel model, çok mesnetli sismik sarsıntılar altında doğrusallaştırılmış zaman tanım alanı çözümleri de dâhil olmak üzere çeşitli analizlere tabi tutulmuştur. Bu genel modele ek olarak, daha ayrıntılı bölgesel modeller (örneğin, kule-payanda bağlantısı vb. için geliştirilmiş modeller) yardımıyla, birkaç daha ayrıntılı doğrusal ve doğrusal olmayan çözüm gerçekleştirilmiştir. Bu çalışmaların sonuçları daha sonra bazı bildiri ve raporlarda yayınlanmıştır (Ingham ve diğ. 1995, Rodriguez ve Ingham 1995, Nader ve Ingham 1995, Imbsen ve Schamber 1999, Gurelli ve Nikias 1995, Nakamura ve diğ. 1993, Dameron ve diğ. 1994). Çok yakın tarihli bir çalışmada, Game ve diğ. (2016) Strand7 (2007) kullanarak GGK'nün 3 boyutlu bir modelini yaratmıştır. Her ne kadar bu modeli işbu makalenin yazarları ile paylaşmış olsalar da, model geometrisi ve detaylarının tam olarak doğru olmamasından ötürü model bu çalışmada kullanılmamıştır.

Bu çalışma kapsamında GGK için yeni bir 3 boyutlu yapı modeli oluşturulmuştur. Bu modelin geometrik anlamda en yüksek hassasiyetle tanımlanabilmesi için köprü geometrisi SketchUp Warehouse sitesinde hazır bulunan GGK modelinden (Şekil 5'te gösterilmiştir) alınmıştır. İlk şeklin yüzeylerinin ve çizgilerinin hassas 3 boyutlu katı elemanlara dönüştürülmesi için model ABAQUS yazılımına (Hibbitt ve diğ. 2001) aktarılmıştır. Oluşturulan yeni model Şekil 8a'da gösterilmektedir. Katı elemanlardan meydana gelen bir modelin önceki bölümde tanımlanan çıktı bazlı tanılama yöntemi hesaplamalarında kullanılması, sebep vereceği işlem yoğunluğundan dolayı, mümkün değildir. Dolayısıyla, bu elemanlar SAP2000'de (CSI 2002) Şekil 8b'de gösterilen yapısal elemanlarla değiştirilmiştir. Söz konusu modeli oluşturmak için, köprüye dair kamuya açık detaylar (Strauss ve Paine 1938) ve önceki bölümlerde derlenen çalışmalarda diğer araştırmacıların belirttiği nicel ve nitel bulgulardan faydalanılmıştır (Şekil 8b).

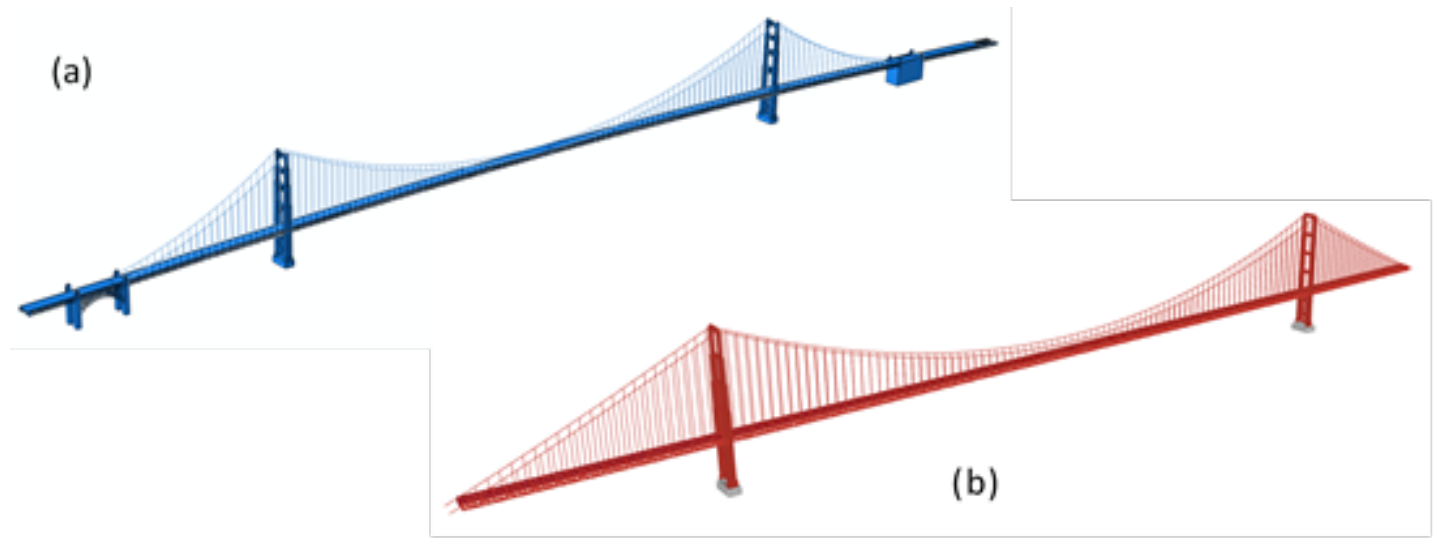

Şekil 8: a) ABAQUS modeli, b) SAP2000 modeli 
Son olarak oluşan SAP2000 modeli, ayrıntıları sonraki bölümde anlatılan paralel işlem çerçevesinden yararlanabilmek adına, SAP2000 uygulama program arayüzü (API)'nü kullanan bir MATLAB (2004) arabirimi ile OpenSEES (McKenna 2011) modellerine dönüştürülmüştür. Bu MATLAB kodu, herhangi bir diğer yapı için bahsi geçen çevirim işleminin tekrarlanmasını mümkün kılacak şekilde tasarlanmıştır. GGK'sü için elde edilen nihai OpenSEES modeli Şekil 9'da gösterilmektedir.

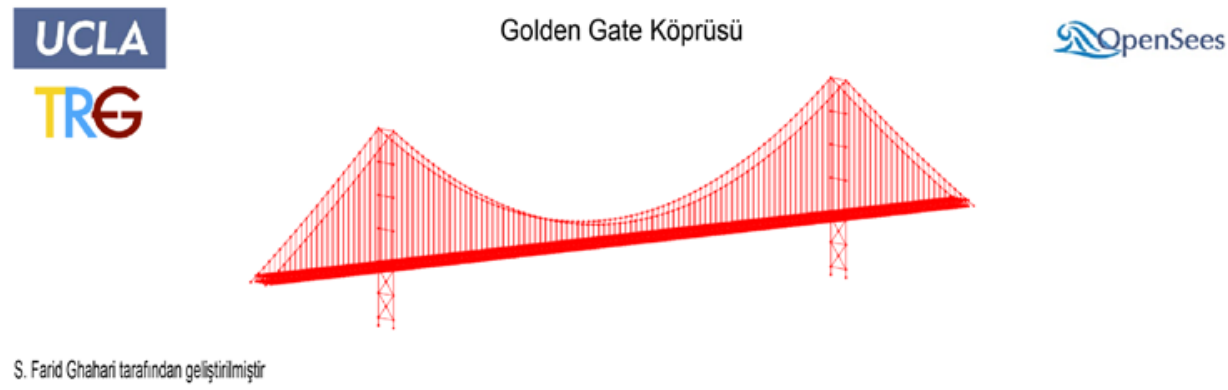

Şekil 9: GGK'nün OpenSEES modeli

OpenSEES modeli, 8000 çerçeve, 2000 alan elemanının birleşiminden oluşan 20000'den fazla serbestlik dereceli bir sistemden meydana gelmektedir. Köprünün SAP2000 modelinde, ana ve askı kabloları kablo elemanları olarak modellenmiş, ana kabloların geometrisi ise yinelemeli olarak ölü yükler yüklendikten sonra Abdel-Ghaffar (1985a) tarafından bildirilen iç gerilim ve maksimum sarkma değerlerine sahip olacak biçimde belirlenmiştir. Köprünün OpenSEES modelinde ise ana ve askı kabloları korotasyonel kafes elemanları ile bu elemanlara öngerilme değerleri tanımlanmasına olanak veren bir malzeme tipi atanması suretiyle, modellenmiştir. Modelde, ana ve askı kablolarındaki sıfır basma kuvveti tanımlaması haricinde, doğrusal olmayan malzeme bulunmasa da doğrusal olmayan geometri etkileri, asma köprülerin yapısal davranışının belirlenmesindeki önemlerinden dolayı hesaba katılmıştır.

\section{4) Paralel İşlem Çerçevesi}

Önerilen yöntemin GGK gibi büyük ölçekli yapılara uygulanması için kayda değer işlemci kapasiteleri gerekmektedir. Bu gereksinim, metodun mühendislik uygulamalarında kullanımını sınırlayan bir faktördür. Örneğin, GGK'nün bilinmeyen TGH'lerinin yalnızca köprünün dört ana ayağında kestirileceği durumda (bkz. Şekil 5), $100 \mathrm{~Hz}$ örnekleme hızında 5 saniyelik zaman pencereleri $\left(t_{1}^{m}: t_{2}^{m}\right)$ kullanılırsa, tüm modelin her bir yineleme adımı için 12001 defa koşturulması gerekir. Her modeli koşturmak için ortalama ${ }^{6} 10$ dakika gerekeceğini varsayarsak, tüm yinelemelerin tamamlanması için yaklaşık 80 gün bir zaman gerekecektir. Her bir zaman penceresinin birden fazla yineleme gerektireceği göz önüne alındığında, önerilen yöntemin olağan sıralı hesaplama yaklaşımları yoluyla kullanımı neredeyse imkânsızdır. Bahsi geçen hatırı sayılır ölçekteki koşturma süresini azaltmak için, bu çalışmada Şekil 10'da şematik bir biçimde tarif edilmiş olan çift paralel işlem çerçevesi önerilmektedir. Bu çerçevenin kullanımı için öncelikle bir SE modeli (bu uygulamada OpenSEES'te (MacKenna 2011) tanımlanmıştır), yapısal çizimler ve Google görüntüleri veya herhangi bir mevcut SE modeli kullanılarak, oluşturulur. İkinci durumda

${ }^{6}$ Analiz koşturma zamanları sabit değildir, ilk pencereden sonuncuya doğru ilerledikçe artış gösterir. 
dönüşüm daha önce de bahsedildiği gibi bir MATLAB (2004) kodu ve SE yazılım program arazyüzü (API) üzerinden yapılır. SE modeli daha sonra OpenSEES'in Tanım Alanı Ayrıştırma ${ }^{7}$ işlevinden yararlanarak $p$ sayıda alt modele ayrıştırılır. Bu sayede her $q$ sayıda yineleme için (örneğin, 12001), OpenSEES modelleri $p \times q$ ayrı çekirdek üzerinde paralel olarak oluşturulup, çalıştırılabilir. Yüksek performanslı hesaplama kaynaklarına erişim her geçen gün daha kolaylaştığından, yeteri kadar işlemci çekirdeğinin mevcut olduğu durumlarda önerilen çerçeve söz konusu 80 günlük koşturma zamanını-özellikle oluşturulan $p$ sayıdaki alt modelin arasındaki etkileşim yükünün sınırlı olduğu durumlarda-1 dk'dan daha az bir süreye düşürebilir. Burada önemli bir husus $p$ için seçilen sayının hesaplama hassasiyetine bir etkisi olmadığı, sadece hesaplamaların paralelleştirilmesi işleminde rol oynadığıdır. Genel olarak, $p$ rakamı hesaplamaların gerçekleştirildiği bilgisayar ortamının işlemci kapasitesine bağlı olarak belirlenir.

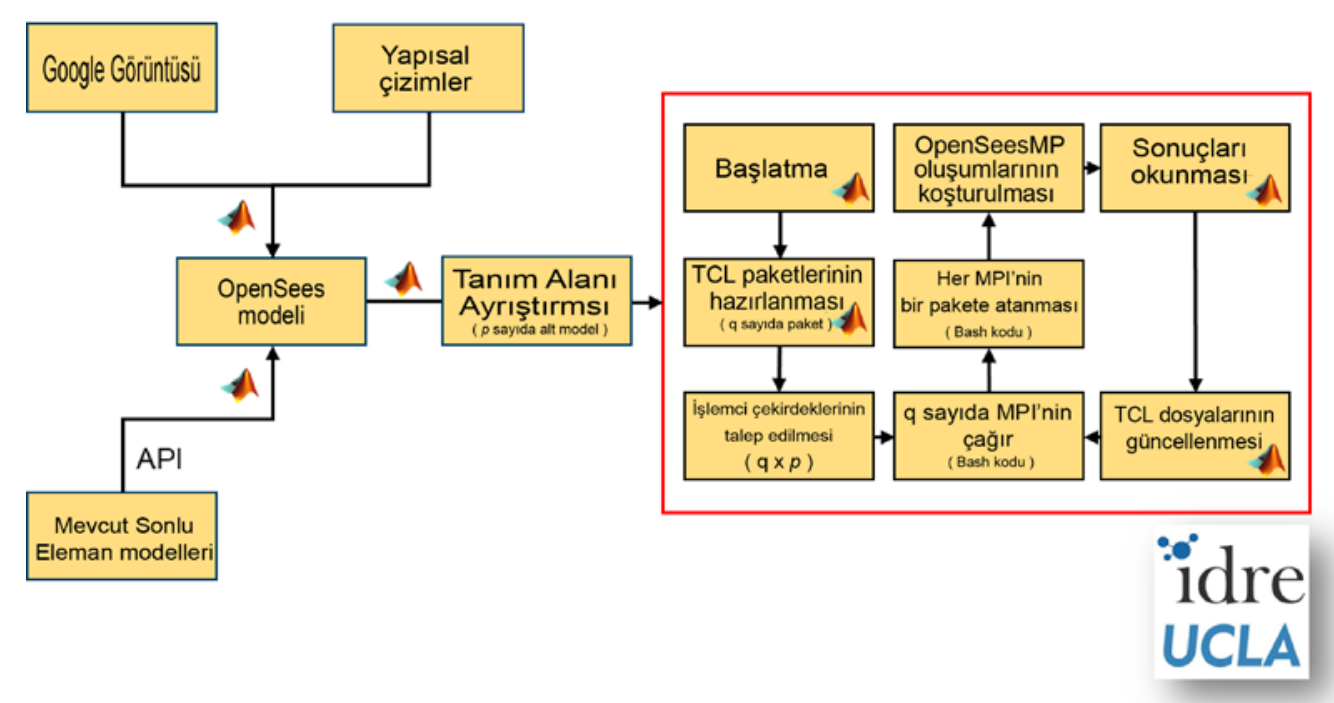

Şekil 10: Tasarlanan çift paralel işlem çerçevesi (Not: MPI mesaj iletme ara yüzü teriminin yaygın olarak kullanılan kısaltmasıdır)

$\mathrm{Bu}$ çalışmadaki hesaplamalar, UCLA'daki Hoffman2 bilgisayar kümesi ile 500 civarında çekirdekle, $p=2$ değeri için, gerçekleştirilebildiğinden aşağıdaki sadeleştirme varsayımlarının yapılmasına gerek duyulmuştur:

- Güney ve kuzey köprü kenar ayaklarındaki TGH'ler, sırasıyla güney ve kuzey payandalardaki TGH'ler ile aynı kabul edilmiştir. Bu varsayım, bilinmeyen girdi deprem hareket sayısını 6'ya düşürmüştür.

- Doğrusal olmayan geometri etkisinin modele tesir eden tek doğrusal olmayan yapısal etken olduğu varsayılmıştır.

- GGK'nün çok esnek bir yapı olmasından ötürü, tanılama işlemi $10 \mathrm{~Hz}$ örnekleme hızı ile yapılmıştır. 5 saniyelik bir pencere uzunluğu kullanıldığı durumda, bu sadeleştirme yineleme başına analiz sayısını $\sim 600$ 'e düşürmektedir. Bu örnekleme hızının elde edilecek sonuçlara etkisinin sınırlı olduğunu kanıtlamak amacıyla, ilgili frekans aralığının 2014

\footnotetext{
${ }^{7}$ Uluslarası literaturde "domain decomposition" olarak tanımlanır.
} 
Ghahari et al. / Turkish Journal of Earthquake Research 1 (2), 98-122, December 2019

Güney Napa depremi kayıtlarının sarsıntı enerjisinin çoğunu içerdiğinden emin olunmuştur. Kayıtlar $5 \mathrm{~Hz}$ alçak geçiren filtre ile süzülmüş ve Şekil 11'de gösterilen, filtreleme işlemi sonrası elde edilen kayıtlar ile asıl kayıtlardan elde edilen, en büyük yerdeğiştirme oranları hesaplanmıştır. Görüleceği üzere bu oran kayıt kanalların çoğu için 0.8 'den yüksektir. Özellikle köprünün asma kısmında (temel, köprü ve kule seviyelerinde) kaydedilen veriler için bu değer 0.9'a yakındır. Burada önemli bir nokta, zaman tanım alanı çözümlerinde sayısal integrasyonun doğruluğunu yüksek tutabilmek amacıyla $100 \mathrm{~Hz}$ örnekleme hızındaki sinyallerin kullanılmış olmasıdır. Bu işlem girdi hareketlerinin ara değerlerinin hesaplanması ile gerçekleştirilir.

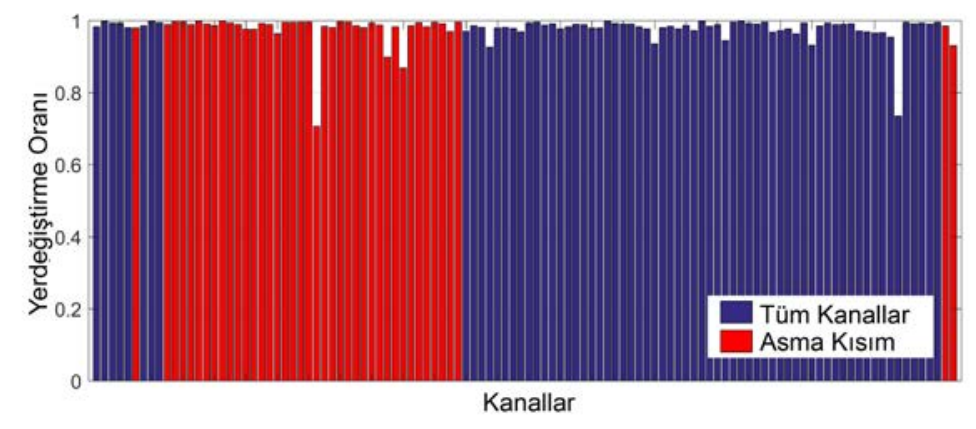

Şekil 11: 2014 Güney Napa depremi kayıtlarının 5 Hz alçak geçişli filtre kullanılarak süçgeçleme ile elde edilen veriler ile asıl verilerden, her bir kayıt kanalı için, hesaplanan en büyük yer değiştirme oranları

\section{4) Tanılanabilirlik}

Herhangi bir tanılama işleminin ilk adımı, olası belirsizlik kaynaklarını ve bu belirsizliklerin tanılanabilirliğini tespit etmektir. Bu çalışmada başlangıç aşamasında tüm malzeme özelliklerinin belirsiz olduğu varsayılmaktadır. Buna ek olarak tüm birleşim noktaları (örneğin tabliye kule bağlantıları) ve sınırlar (zemin-köprü ayağı ve zemin-temel sistemleri gibi), tanılama sürecinde güncellenmek üzere olası yay rijitlik değerlerine göre tanımlanan, doğrusal yaylarla modellenmiştir. Ayrıca, yapısal sönümleme davranışı, şu anda sönümleme modellemesi için mümkün olan en iyi yaklaşım olan, Rayleigh sönümlemesi ile sönüm parametrelerinin tanılama sürecinde belirlenmeye aday değişkenler olarak belirtilmesi suretiyle, hesaplara dâhil edilmiştir. Böylece toplamda, TGH'ler dâhil 66 parametre tanılama işleminde belirlenmesi olası değişkenler olarak tanımlanmıştır. Tanılama işlemleri için gerekli işlemci yükü ve bazı parametrelerin birbirlerine bağlı olduğu göz önünde bulundurulduğunda, tanılama sürecinde bu parametrelerin tamamını ele almak mümkün değildir, lakin gerekli de değildir. Aşağıda belirtilen iki aşamalı eleme yöntemiyle, güncelleme parametrelerinin sayısı önemli ölçüde azaltılmıştır. İlk aşamada, hangi parametrelerin yapı davranışının anlaşılabilmesi için önemli, hangilerinin serbest veya sabit olduğu tespit edilmiştir. Örneğin yapısal çizimler ve önceki çalışmalarda belirtildiği üzere, GGK'nün ana/yan açıklıkları ve kuleler arasındaki mevcut birleşim detayları göreli dönmelere izin vermediğinden, SE modelinde bu bağlantı bileşenleri sabit tanımlanmış ve tanılama sürecinden çıkarılmıştır. Bu bileşenlerin sabit olmadığı varsayımı yapılması durumunda, modelin modal özelliklerini önceki çalışmalarda belirtilen değerlerle eşleştirmek mümkün olmayacaktır. GGK'nün yapısal davranışında eylemsizlik ZYE etkilerinin önemli olmayacağı bekleniyor olsa dahi, SE modelinde, zemin-temel sistemlerine öteleme ve dönme yayları atanmış ve bu yayların rijitlikleri bilinmeyen parametreler olarak kabul edilmiştir. Bununla birlikte, bu yayları etkili kılmak için yay rijitlik değerlerinin, GGK'nün diğer yapısal özelliklerine göre fiziksel olarak anlamlı olmayacak 
düzeyde düşük tutulması gerekmektedir. Bu nedenle bu değerler de sabitlenmiştir. Ana ve askı kablolarındaki ön gerilim, ölü yüklerin yüklenmesi sırasında detaylı bir biçimde hesaba katılıklarından, tanılama sürecinin kapsamına alınmamıştır. Bu bilgi ve tahkikler ışığında, önceden 66 olarak belirlenen tanılama parametrelerinin sayısı 28'e indirilmiştir. Tablo 2'de bahsi geçen 28 olası potansiyel güncelleme parametresi listelenmiştir. Bu parametrelerin tümünün mevcut alet düzeni ile tanılanması mümkün olamayabileceğinden, ikinci eleme aşamasında, bu parametrelerin tanılanabilirliğini belirlemek maksadıyla duyarlılık analizi yapılmış ve her parametre $\left(\theta_{i}\right)$ 'nin toplam bilgisi aşağıdaki gibi hesaplanmıştır (Reid 1977).

$$
\mathbf{I}_{i}=\sum_{j=1}^{m}\left(\frac{\partial y_{j}}{\partial \theta_{i}}\right)^{2}, \quad i=1 \ldots 28
$$

Bu bağıntıda $\partial y_{j} / \partial \theta_{i}$, $j$ 'inci kanalın $\theta_{i}$ 'ye göre hassasiyet tepkisi, $m$ ise kaydedilen tüm kayıt kanalların sayısıdır. $\partial y_{j} / \partial \theta_{i}$ ' 'nin hesaplanması için $\theta_{i}$. nominal değeri etrafında pertürbe edilmiş ve kısmi türev sonlu farklar yöntemi ile ayrıklaştırılmıştır. Şekil 12a, tüm bu 28 parametrenin her biri için belirlenen bilgi entropi değerlerini göstermektedir. Parametrelerin tanılama sürecindeki önemlilik düzeylerinin bilgi entropisi cinsinden 1 eşik değeri ile tespit edilebileceği kabul edildiği durumda, toplamda 7 parametrenin bu tanılama uygulaması için en önemli olduğu sonucuna varmak mümkündür. Söz konusu şekil göstermektedir ki, bu model ve sensör düzenini kullanarak köprü kenar ayak yayları hakkında güvenilir bilgi elde etmek mümkün değildir. Bunun ana sebebinin köprünün yapısal anlamda çok esnek olmasından kaynaklandığı düşünülmektedir.

Durum böyle olsa bile, bu 7 parametrenin her birini özgün bir biçimde tanılamak olanaksızdır. Şekil 12b'de görüldüğü gibi parametreler arasındaki karşılıklı bilgi değerlerine bakıldığında, bazı parametrelerin birbirleriyle yüksek seviyede ilişkili olduğu görülebilir. Örneğin, tabliye yan kirişlerinin esneklik modülü, çapraz bağlantıların elastisite modülü ile ilişkilidir. Bu durumda bu parametrelerden biri (çapraz bağlantılar) sabit, diğeri (tabliye kirişleri) güncelleme parametresi olarak kabul edilebilir. Ayrıca askı ve tabliye elastisite modüllerinin, büyük ölçüde, çapraz bağlantı elastisite modülüyle ilişkili olmasından ötürü, askı kablo ve tabliye parametrelerini sabit kabul edip çapraz bağlantıların elastisite modülünü güncelleme parametresi olarak kullanmak mümkündür. Bu gözlemler sonucunda, mevcut sensör düzeni ile kaydedilmiş veriler kullanıldığında, tanılanması gerekli ve mümkün parametre sayısı 4'e indirgenebilir. Bu parametreler kule, ana kablo, tabliye yan kiriş ve tabliye alt destek elastik modülleridir. Her ne kadar sönümleme parametreleri, alpha ve beta, göz önünde bulundurulan parametreler ile ilişkilerinin sınırlı olmasından ötürü, belirlenen diğer 4 parametre kadar yüksek bilgi entropi değerlerine sahip olmasada, bu çalışmada her iki parametre de hesaplamalara dâhil edilmiştir. Böylece tanılama işleminin, her payandada 3 bileşenden oluşmak üzere, $6 \mathrm{TGH}$ zaman serisi ve 6 bilinmeyen değişken için gerçekleştirilmesine karar kılınmıştır.

\section{5) Tanılama Sonuçları}

Geliştirilen yöntem, doğrusal ve doğrusal olmayan, girdi-çıktı (IO) ya da yalnızca-çıktı (OO) durumları da dâhil çok çeşitli uygulamalar için kullanılabilir. Bu çalışmada önerilen yöntem, ön deneme olarak, girdi-çıktı tanılaması için kullanılmıştır. Bu tarz girdi-çıktı tanılaması tatbikleri mühendislik uygulamaları açısından büyük önem taşır, zira zemin-yapı etkileşimi etkilerini doğru bir biçimde göz önünde bulundurmanın bir yolu da analizlerde kullanılan girdi hareketlerini geri besleme eylemsizlik etkilerine göre düzeltmektir. Başka bir deyişle, temel seviyesinde herhangi bir noktada oluşacak girdi hareketinin hesaplanabildiği durumlarda, o noktanın ötesindeki zemin 
Ghahari et al. / Turkish Journal of Earthquake Research 1 (2), 98-122, December 2019

esneklik davranışını doğrudan modellemeye gerek kalmadan, YZE etkileri doğru bir biçimde hesaplara dâhil edilebilir. Örneğin Shirkhande ve Gupta (1999), benzer bir yaklaşımı izleyerek,

Tablo 2: Illk eleme aşaması sonrası belirlenen tanılama aday parametreleri

\begin{tabular}{ccc}
\hline No & Eleman & Parametre \\
\hline 1 & Tabliye Alt Destekleri & Elastisite Modülü \\
2 & Ana Kablolar & Elastisite Modülü \\
3 & Tabliye Yan Kirişleri & Elastisite Modülü \\
4 & Tabliye & Elastisite Modülü \\
5 & Çapraz Bağlantılar & Elastisite Modülü \\
6 & Tabliye Enine Kirişleri & Elastisite Modülü \\
7 & Askı Kabloları & Elastisite Modülü \\
8 & Diz Destekleri & Elastisite Modülü \\
9 & Tabliye Üst Destekleri & Elastisite Modülü \\
10 & Kule Yapısı & Elastisite Modülü \\
11 & Ray Kirişleri & Elastisite Modülü \\
12 & Enine Dikmeler & Elastisite Modülü \\
13 & Dikey İnce Çubuklar & Elastisite Modülü \\
14 & Dikey Kalın Çubuklar & Elastisite Modülü \\
15 & Güney Kulesi-Güney Tarafı Açıklığı & Yay Rijitliği, M2 \\
16 & Kuzey Kulesi-Kuzey Tarafı Açıklığı & Yay Rijitliği, M2 \\
17 & Güney Köprü Kenar Ayağı & Yay Rijitliği, P \\
18 & Güney Köprü Kenar Ayağı & Yay Rijitliği, V2 \\
19 & Güney Köprü Kenar Ayağı & Yay Rijitliği, V3 \\
20 & Güney Köprü Kenar Ayağı & Yay Rijitliği, T \\
21 & Güney Köprü Kenar Ayağı & Yay Rijitliği, M2 \\
22 & Kuzey Köprü Kenar Ayağı & Yay Rijitliği, P \\
23 & Kuzey Köprü Kenar Ayağı & Yay Rijitliği, V2 \\
24 & Kuzey Köprü Kenar Ayağı & Yay Rijitliği, V3 \\
25 & Kuzey Köprü Kenar Ayağı & Yay Rijitliği, T \\
26 & Kuzey Köprü Kenar Ayağı & Yay Rijitliği, M2 \\
27 & Yapı Sönümlemesi & Alfa \\
28 & Yapı Sönümlemesi & Beta \\
\hline & &
\end{tabular}

modellerini temel seviyesinde sabitleyerek GGK'nün yapısal davranışını hesaplamıştır. Buna ek olarak, eğer girdi-çıktı tanılaması sırasında zemin-temel parametrelerine ek olarak üst yapı parametreleri de kestirilirse, bu bilgiler yoluyla yalnızca-çıktı (OO) tanılaması hesaplarının karmaşıklığı da ciddi ölçüde azaltılabilir. Kuşkusuz bu son yaklaşım sadece temel seviyesinde deprem kayıtlarının olduğu durumlara mahsustur. Önerilen girdi-çıktı tanılaması GGK'nün simüle edilmiş verilerine uygulanmıştır. Şekil 13, belli başlı kanallarda (yapay olarak simüle edilerek) kaydedilen ve (nihai güncelleme adımının son yinelemesinde) öngörülen yapısal davranışların kıyaslamasını yapmaktadır. Görüldüğü gibi, öngörülen veriler kaydedilmiş sinyal değerlerini neredeyse kusursuz bir biçimde yakalamaktadır. 6 parametrenin tamamında $\% 50$ başlangıç hatası olduğu varsayılmış olsada, nihai sonuçların elde edildiği en son güncelleme adımı sonunda yöntem bu parametrelerin hata oranlarını \%0.03, \%0.04, \%0.23, \%1.59, \%2.38 ve \%13.76 değerlerine indirebilmiştir. Şekil 12a'da da gösterildiği gibi, beklendiği üzere sönüm parametreleri 
diğer parametreler kadar yüksek kesinlikle tanılanamamış; rijitlik-orantılı faktörde hata oranlarının daha yüksek olduğu gözlenmiştir.
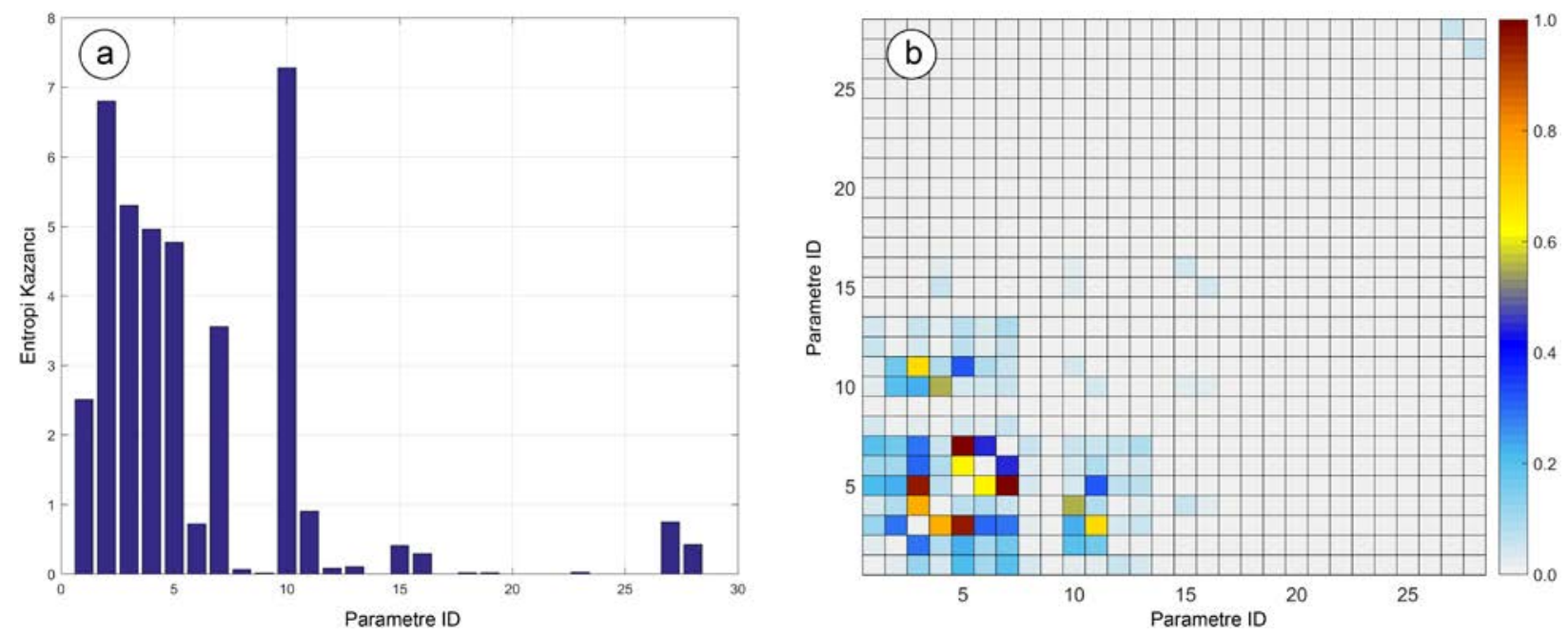

Şekil 12: Tanılanabilirlik analizi sonuçları: a) her parametre için belirlenen bilgi entropisi ve b) parametreler arası karşılıkı bilgi değerleri

Yalnızca-çıktı tanılamasındaki belirsizlikleri azaltmak için girdi-çıktı tanılama sürecinden elde edilen bilgileri kullanmak mümkün olsa bile, bu çalışmada böyle bir yaklaşım benimsenmemiştir. $\mathrm{Bu}$ karar çoğu zaman gerçek hayatta köprü ayaklarının tamamında yapısal davranışa dair ölçümler bulunmayacağı gözlemine dayanmaktadır. Bu nedenle, yalnızca-çıktı tanılaması burada TGH'ler dâhil 6 parametrenin tümünün bilinmediğini varsayarak gerçekleştirilmiştir. \%25'lik başlangıç hatası ile kule, ana kablo, tabliye yan kiriş ve desteklerin elastisite modülleri, buna ek olarak kütle ve rijitlik orantılı sönüm katsayısı ve rijitlik orantılı sönüm katsayıları sırasıyla $\% 0.05$, $\% 3.51, \% 0.19, \% 0.01, \% 8.47$ ve \%16.33 hata oranlarıla elde edilmiştir. Belli başlı kanallarda kaydedilen ve öngörülen yapısal tepkiler arasındaki kıyaslama Şekil $14{ }^{\prime}$ te $^{8}$ gösterilmiştir. Görüldüğü gibi parametrelerden birinin doğru tanılanamadığı durumda dahi, öngörülen davranış sinyalleri kaydedilenlere çok yakındır.

$\mathrm{Bu}$ çalışmanın belki de en önemli tanılama sonuçları TGH'lerdir. Tanılanan TGH'ler ve bu sinyallere karşılık gelen kaydedilmiş sinyaller Şekil 15'te kıyaslanmıştır. Şekilden de görülebileceği üzere, önerilen yöntem aracılıyla girdi kayıtları yüksek hassasiyette tanılanabilmiştir.

\section{SONUÇLAR}

Bu çalışma, uzamsal olarak seyrek bir şekilde ölçülmüş sismik yapı davranış kayıtlarını kullanarak köprü yapılarının eş zamanlı sistem ve girdi tanılaması için yenilikçi bir çerçeve sunmaktadır. Köprü yapıları, nispeten uzun mesafeler geçmek üzere tasarlanan yapılar olduğundan ötürü, yer hareketlerinin uzamsal değişkenliğine diğer birçok yapı türüne göre daha hassastırlar. Bu nedenle, deprem girdi hareketinin ölçümü, özellikle birden çok ayaktan oluşan uzun köprüler için zorlu bir iştir. Ayrıca, köprü temel giriş hareketlerinin (TGH'ler) doğrudan ölçümü hem eylemsizlik hem de kinematik zemin-yapı etkileşimi etkilerinden dolayı mümkün olmayabilir. Bu çalışma kapsamında

${ }^{8}$ Şekil 14’te, şekil 13'e göre farklı sönüm değerleri kullanılmış olmasından dolayı, kaydedilen kayıt sinyallerinde ufak farklılıklar gözlemlenebilir. 
önerilen tanılama yöntemi, bilinmeyen TGH'lere ek olarak köprülerin tam olarak belirlenmesi mümkün olmayan bazı parametrelerini de tahmin edebilecek şekilde yalnızca-çıktı tanılaması yapabilir niteliktedir. Yöntem herhangi bir hesaplama karmaşıklığındaki köprü yapısına uygulanabilecek pratiklikte bir çift paralel işlem çerçevesinden meydana gelmektedir. Yöntemi doğrulamak için, Golden Gate Köprüsünün ayrıntılı bir sonlu eleman modeli oluşturulmuş ve bu model yardımıyla, 2014 Güney Napa depreminin yapı üzerinde kaydedildiği noktalar için, yapısal davranış hesaplanmıştır. Çalışmanın sonuçları, önerilen analitik çerçevenin TGH'leri yapısal anlamda karmaşık bir köprünün uzamsal olarak seyrek bir şekilde ölçülmüş sismik yapı davranış kayıtlarını kullanarak oldukça yüksek bir hassaslıkla yakalayabildiğini göstermektedir. Yazarların mevcut literatür bilgisine göre, bu çalışma, bir köprü yapısının gerçek deprem kayıtlarının kullanılmasıyla birden fazla TGH'nin aynı anda tanılandığı tek çalışmadır, dolayısıyla buradaki bulgular ayrı bir öneme sahiptir.

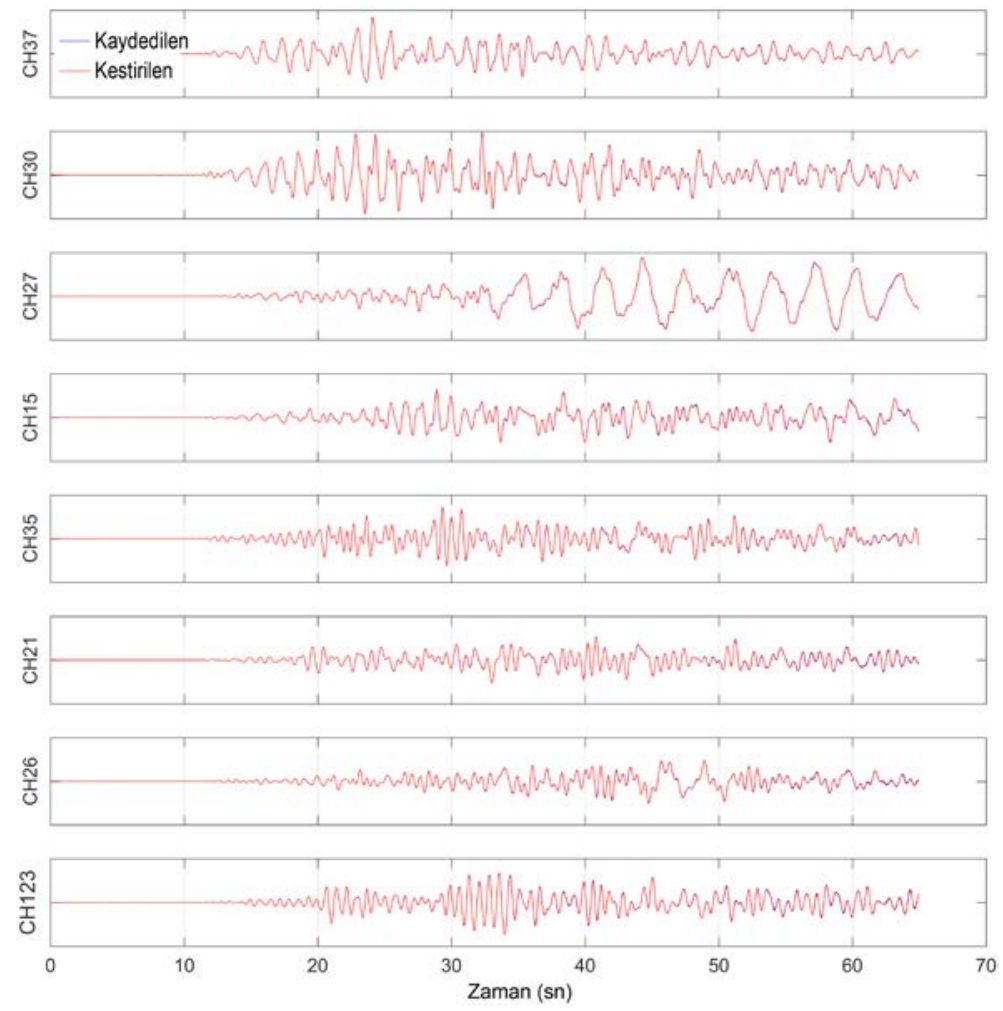

Şekil 13: Belli başlı kanallarda simüle edilmiş ve öngörülen ivme tepkilerinin karşılaştırılması (IO durumu) 
Ghahari et al. / Turkish Journal of Earthquake Research 1 (2), 98-122, December 2019
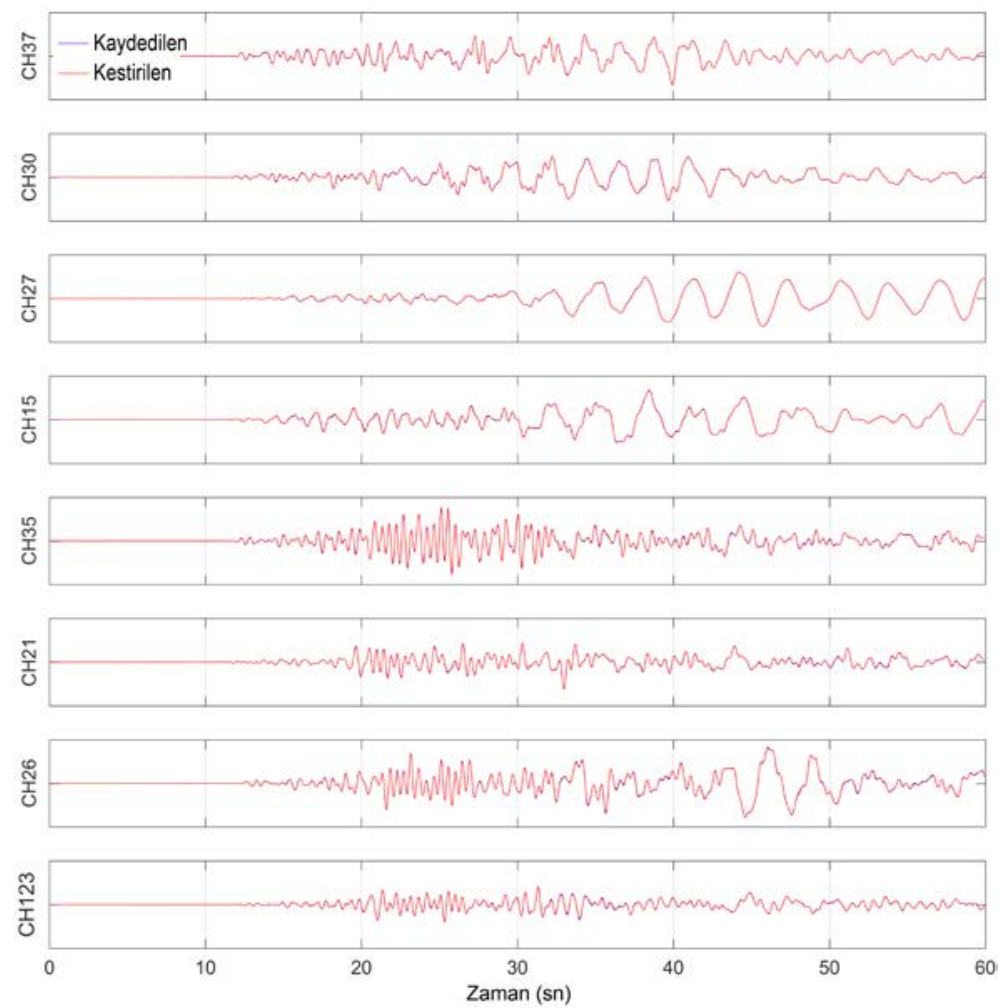

Şekil 14: Belli başı kanallarda simüle edilmiş ve öngörülen ivme tepkilerinin karşılaştırılması (OO durumu)
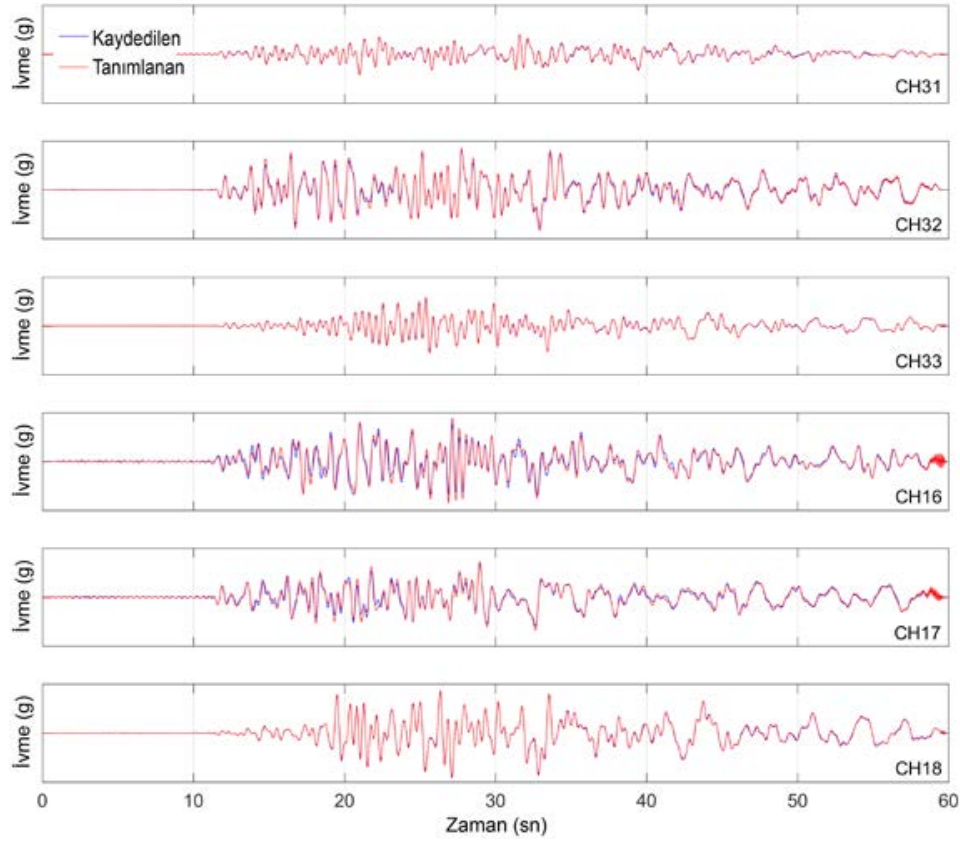

Şekil 15: Kesin ve tanılanmış TGH sinyallerinin kıyaslaması 


\section{TEŞEKKÜR}

Yazarlar, UCLA Dijital Araştırma ve Eğitim Enstitüsü'nden Dr. D'Auria'ya, buradaki analizlerin UCLA Hoffman bilgisayar kümesi üzerinden yapılmasına yardımcı olduğu için teşekkür eder. Bu yazıda sunulan çalışmalar, kısmen Kaliforniya Jeolojik Araştırma Kurumu (Sözleşme No: 1014963) ve Kaliforniya Eyaleti Ulaşım Dairesi Başkanlığı (Destek No: 65A0450) tarafından finanse edilmiştir. Bu çalışmada ifade edilen görüşler, bulgular, sonuçlar veya tavsiyeler yazarlara aittir ve destekleyen kurumların görüşlerini yansıtmaz.

\section{KAYNAKLAR}

Abdel-Ghaffar A.M., 1976. Dynamic analyses of suspension bridge structures, California Institute of Technology Earthquake Engineering Research Laboratory (Unpublished), Pasadena California.

Abdel-Ghaffar A.M., Rubin L.I., 1983a. Vertical seismic behaviour of suspension bridges, Earthq. Eng. Struct. Dyn. 11 (1), 1-19.

Abdel Ghaffar A.M., Rubin L.I., 1983b. Lateral Earthquake Response of Suspension Bridges, J. Struct. Eng. 109 (3), 664-675.

Abdel-Ghaffar A.M., Scanlan R.H., 1985a. Ambient vibration studies of golden gate bridge: I. Suspended structure, J. Eng. Mech. 111 (4), 463-482.

Abdel-Ghaffar A.M., Scanlan R.H., 1985b. Ambient Vibration Studies of Golden Gate Bridge: II. Pier-Tower Structure, J. Eng. Mech. 101 (4), 483-499.

Abdel-Ghaffar A.M., Scanlan R.H., Diehl J., 1985. Analysis of the dynamic characteristics of the Golden Gate Bridge by ambient vibration measurements. Princeton University.

Abdel-Ghaffar A.M., Stringfellow R.G., 1984a. Response of suspension bridges to travelling earthquake excitations: Part I. Vertical response, Int. J. Soil Dyn. Earthq. Eng. 3 (2), 62-72.

Abdel-Ghaffar A.M., Stringfellow R.G., 1984b. Stringfellow, Response of suspension bridges to travelling earthquake excitations: Part II-lateral response, Int. J. Soil Dyn. Earthq. Eng. 3 (2), 7381.

Astroza R., Ebrahimian H., Li Y., Conte J.P., 2017. Bayesian nonlinear structural SE model and seismic input identification for damage assessment of civil structures, Mech. Syst. Signal Process 93, 661-687.

Bendat J.S., Piersol A.G., 1993. Engineering applications of correlation and spectral analysis, 2nd Ed., Wiley, NY, USA, 458 pp.

Baron F., Arikan M., Hamati R.E., 1976. The effects of seismic disturbances on the Golden Gate Bridge. University of California, College of Engineering, Earthquake Engineering Research Center.

CESMD, 2017. Center of Engineering Strong Motion Data.

Erişim adresi: www.strongmotioncenter.org , (01/01/2017) 
Ghahari et al. / Turkish Journal of Earthquake Research 1 (2), 98-122, December 2019

Chang M., Pakzad S.N., 2013. Modified Natural Excitation Technique for Stochastic Modal Identification, J. Struct. Eng. 139 (10), 1753-1762.

CSI, 2002. Integrated Finite Element Analysis and Design of Structures Basic Analysis Reference Manual, Comput. Struct. Inc., Berkeley, California, USA.

Çelebi M., 2012. Golden Gate Bridge response: a study with low-amplitude data from three earthquakes, Earthquake Spectra 28 (2), 487-510.

Dameron R.A., Dunham R.S., Castro J.C., 1994. Nonlinear analysis and experimental validation of a stiffening truss chord of the golden gate bridge, in Computing in Civil Engineering (New York), (2), 1106-1114.

Ebrahimian H., Astroza R., Conte J.P., de Callafon R.A., 2017. Nonlinear finite element model updating for damage identification of civil structures using batch Bayesian estimation, Mech. Syst. Signal Process 84, 194-222.

Game T., Vos C., Morshedi R., Gratton R., Alonso-Marroquin F., Tahmasebinia F., AlonsoMarroquin F., 2016. Full dynamic model of Golden Gate Bridge, in AIP Conference Proceedings 1762 (1), p. 20005.

Gurelli M.I., Nikias C.L., 1995. EVAM: An Eigenvector-Based Algorithm for Multichannel Blind Deconvolution of Input Colored Signals, IEEE Trans. Signal Process. 43 (1), 134-149.

Haykin S., 2001. Kalman Filters (In: Kalman Filtering and Neural Networks, Editor: Haykin S., John Wiley \& Sons Inc., USA, 280 p, doi 10.1002/0471221546), 1-21.

Hibbitt, Karlsson, Sorensen, 2001. ABAQUS/standard User's Manual 1., Pennsylvania State University, USA.

Huang M., Hipley P., Shakal A., 2013. Seismic Instrumentation of Toll Bridges in California, in Sevnetgh National Seismic Conference on Brdiges and Highways, Oakland, Californa, Paper 2013, p10.

Imbsen R., Schamber R., 1999. Seismic retrofit of the north approach viaduct of the Golden Gate Bridge, Transp. Res. Rec. J. Transp. Res. Board (1688), 154-162.

Ingham T.J., Rodriguez S., Nader M.N., Taucer F., Seim C., 1995. Seismic retrofit of the golden gate bridge in Proc., National Seismic Conf. on Bridges and Highways: Progress in Research and Practice, 1995.

Julier S.J., Uhlmann J.K., 1997. New extension of the Kalman filter to nonlinear systems, Proceeding SPIE 3068, Signal Processing, Sensor Fusion, and Target Recognition VI, doi.org/10.1117/12.280797, 182-193.

Ketchum M.A., Seim C., 1990. Golden Gate bridge seismic evaluation, TY Lin International.

Kiureghian A.D., 1996. A Coherency Model for Spatially Varying Ground Motions, Earthq. Eng. Struct. Dyn. 25, 99-111. 
Ghahari et al. / Turkish Journal of Earthquake Research 1 (2), 98-122, December 2019

Ljung L., 1987. System Identification - Theory for the User, Prentice-Hall, Englewood Cliffs, N.J., USA.

Matarazzo T.J., Pakzad S.N., 2014. Modal identification of golden gate bridge using pseudo mobile sensing data with STRIDE, in Dynamics of Civil Structures, Vol. 4, Springer, 293-298.

Matarazzo T.J., Pakzad S.N., 2016. STRIDE for structural identification using expectation maximization: iterative output-only method for modal identification, J. Eng. Mech. 142 (4), p. 4015109.

McKenna F., 2011. OpenSees: a framework for earthquake engineering simulation, Comput. Sci. Eng. 13 (4), 58-66.

Matlab, 2004. MATLAB The Language of Technical Computing, Components 3 (7), 750.

Nader M., Ingham T.J., 1995. Seismic Retrofit of the Towers of the Golden Gate Bridge, in Proceedings of the National Seismic Conference on Bridges and Highways, San Diego, CA, December.

Nakamura Y., Kiureghian A.D., Liu D., 1993. Multiple-support response spectrum analysis of the Golden Gate Bridge 93 (5). Earthquake Engineering Research Center, University of California, USA.

Nishkian L.H., 1947. Vertical vibration recorders for the Golden Gate Bridge, Bull. Seismol. Soc. Am. 37 (2), 81-88.

Pakzad S.N., Fenves G.L., 2009. Statistical Analysis of Vibration Modes of a Suspension Bridge Using Spatially Dense Wireless Sensor Network, J. Struct. Eng. 135 (7), 863-872.

Pakzad S.N., Fenves G.L., Kim S., Culler D.E., 2008. Design and Implementation of Scalable Wireless Sensor Network for Structural Monitoring, J. Infrastruct. Syst. 14 (1), 89-101.

Pakzad S.N., Rocha G.V., Yu B., 2011. Distributed modal identification using restricted auto regressive models, Int. J. Syst. Sci. 42 (9), 1473-1489.

Reid J.G., 1977. Structural Identifiability in Linear Time-Invariant Systems, IEEE Trans. Automat. Contr. 22 (2), 242-246.

Rodriguez S., Ingham T.J., 1995. Seismic protective systems for the stiffening trusses of the Golden Gate Bridge, in Proceedings of the National Seismic Conference on Bridges and Highways.

Seim C., Ketchum M., 1990. Golden Gate Bridge Mass Transit Feasibility Study, Golden Gate Bridge, Highway and Transportation District, San Francisco, California.

Seim C., Rodriguez S., 1993. Seismic performance and retrofit of the Golden Gate bridge, in Structural Engineering in Natural Hazards Mitigation, 133-138. 
Ghahari et al. / Turkish Journal of Earthquake Research 1 (2), 98-122, December 2019

Shakal A.F., Petersen C.D., Cramlet A.B., Darragh R.B., 1995. CSMIP near-real-time strong motion monitoring system: Rapid data recovery and proceZYEng for event response, In Proceedings SMIP95 Seminar on Seismological and Engineering Implications of Recent StrongMotion Data.

Shrikhande M., Gupta V.K., 1999. Dynamic soil-structure interaction effects on the seismic response of suspension bridges, Earthq. Eng. Struct. Dyn. 28 (11), 1383-1403.

Strand7, 2007. Finite Element Analysis System. Strand7 Software Sydney, Australia.

Strauss J.B., Paine C.E., 1938. The Golden Gate Bridge: report of the chief engineer to the Board of directors of the Golden Gate Bridge and Highway and Transportation District, San Francisco, California, USA, $246 \mathrm{p}$.

Tanaka H., Davenport A.G., 1983. Wind-Induced Response of Golden Gate Bridge, J. Eng. Mech. 109 (1), 296-312.

Vincent G.S., 1962. Golden Gate bridge vibration studies, Trans. Am. Soc. Civ. Eng. 127 (2), 667701.

Vincent G.S., Labse M., 1962. Correlation of predicted and observed suspension bridge behavior, Trans. Am. Soc. Civ. Eng. 127 (2), 646-666.

Wolf J.P., Deeks A.J., 2004. Foundation vibration analysis: A strength of materials approach, Butterworth-Heinemann Publ.Comp, U.K., ISBN 978-0750661645, 240 p.

Zerva A., Zervas V., 2002. Spatial variation of seismic ground motions: An overview, Appl. Mech. Rev. 55 (3), 271. 